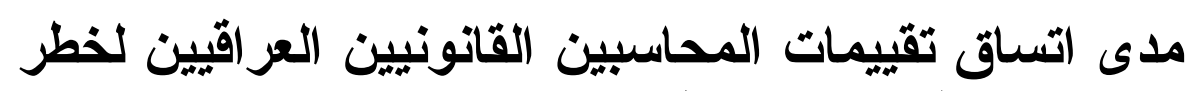

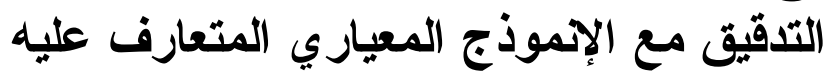

\author{
الاكتور محمد هادي العدناني \\ قسم المحاسبة - كلية الآدارة و الاقتَّاد \\ جامعة السليمانية \\ Hadi9451@yahoo.com
}

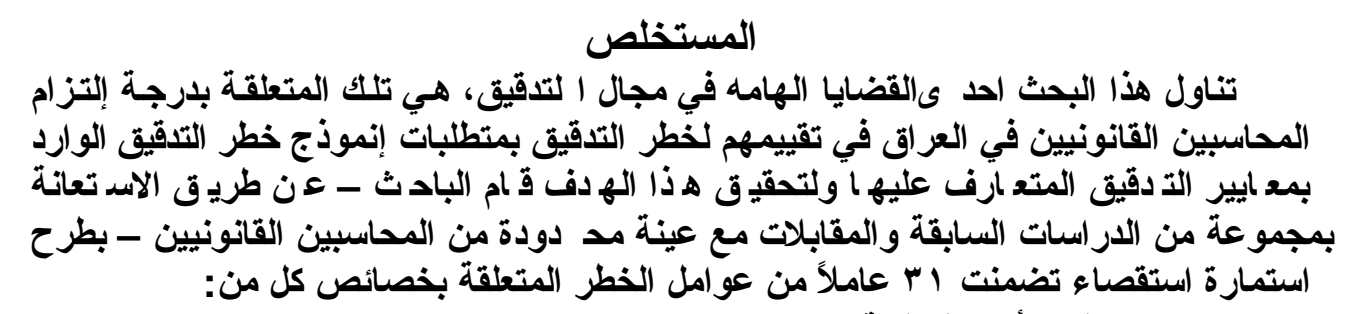

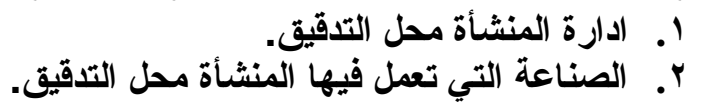
r. ب. المنشأة محل التدقيق. ع. علية التدقيق.

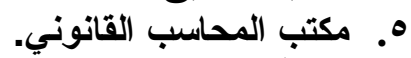

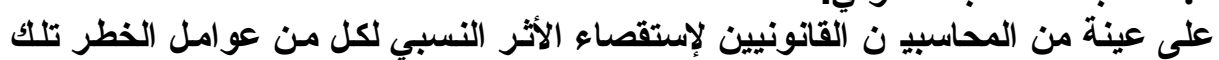

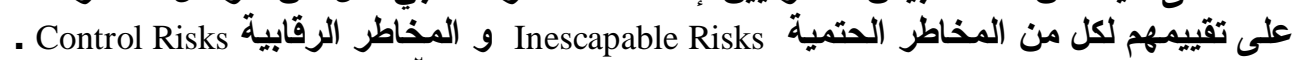

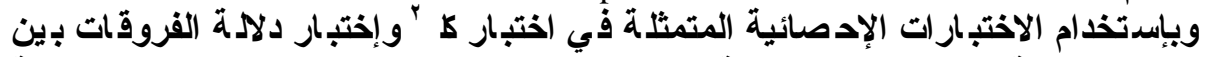

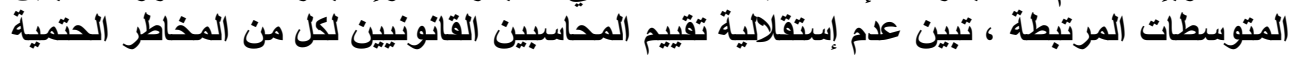

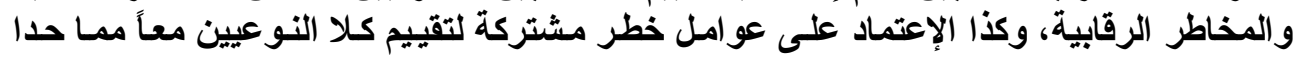

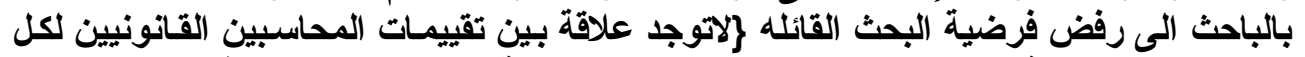

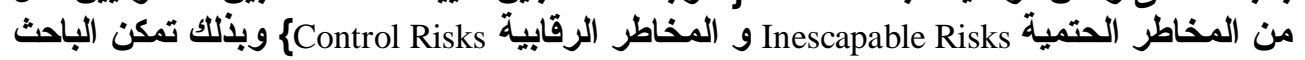
من استخلاص بعض النتائج التي تمخض التخد البحث عنها وأهمها.

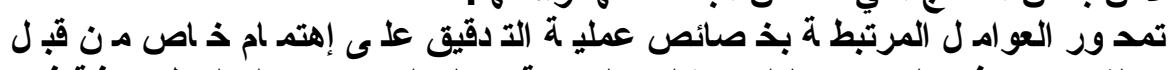

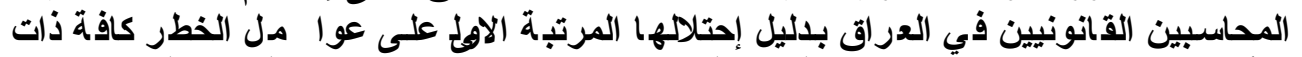

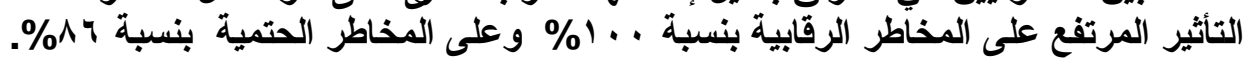

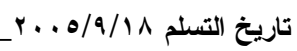




\title{
The Consistency Range of the Iraqi Legal Accountants Evaluation for Auditory Risk A Normative Model
}

\author{
Mohammed H. Al-Adnani, PhD
}

University of Sulaimaniyya

\begin{abstract}
The current research tackled one of the most essential issues in auditory that are related to the degree of commitment to the legal accountants in Iraq, within their evaluation to the auditory risks. The requirements of the auditory risks model are included in terms of the paradigms of known auditory standards. In order of achieve this target, the researcher made a distribution of questionnaire via literatures, interviews and references with a sample of legal accountants in general. In addition to distribute a list contains 31 risk factors, as follows:

1. Establishment administration, the place of auditory.

2. The field of industry that the establishment working in.

3. The establishment, the place of auditory.

4. The operation of auditory.

5. The office of legal accountant.

A sample of legal accountants has been subjected to the type of investigating the relative effect of each of risk factor on the inescapable risks and control risks. Statistical analysis has been followed (Ka and the difference indicator of the relative mediums). It is concluded that there is a sort of independence among the accountants for each inescapable and control risks, and the dependence on the cooperative factors to evaluate both factors. This lead to denouncement of this hypothesis by the researcher that is (there is no relationship between the legal accountants for each Inescapable Risks and Control Risks. Hence, the researcher concluded some results that should be taken into account. The related factors are interconnected with the properties of the auditory operations by a great interest of legal accountants in Iraq; on evidence, that it takes the cum laude among the high risk factors (\%100) and inescapable risks (\%86).
\end{abstract}

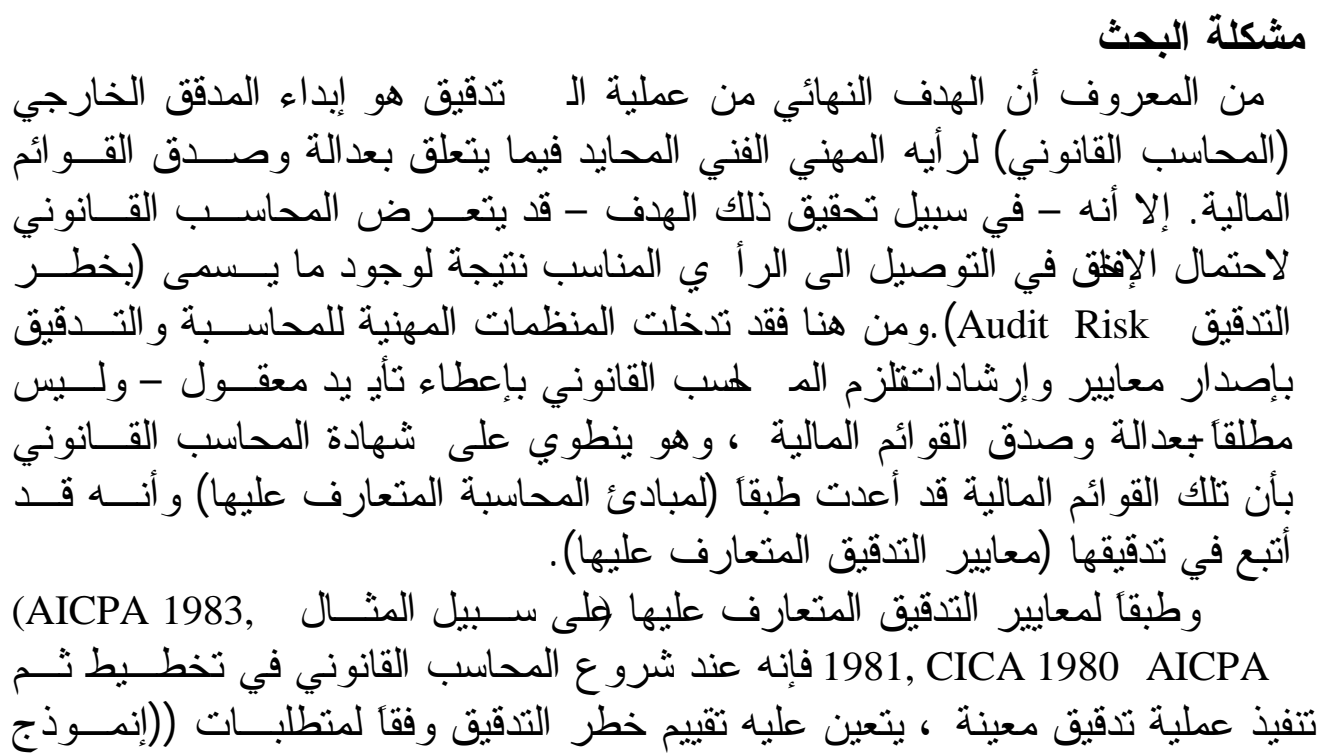


خطر التدقيق)) ولتحقيق هذا الهذف يتطلابنملذج خطر التذقيق مــن المحاســــ ين

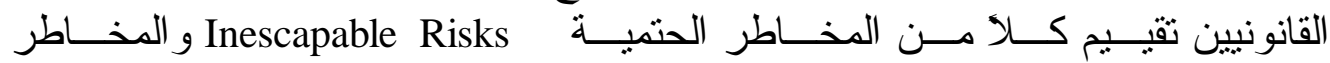
الرقابية Control Risks بوصفهم مستقلين، مع ضرورة الأخذ في الحسبان مكونـات الخطر كافة الخاصة بكل منهما على حده.

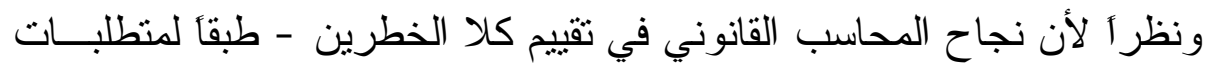

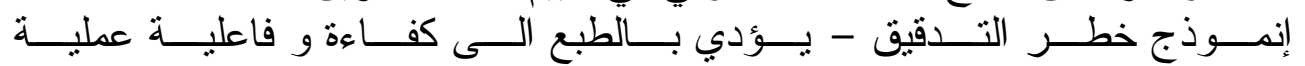

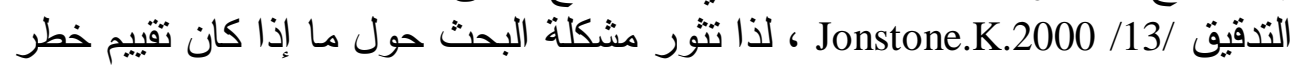

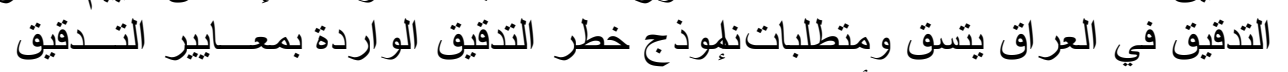

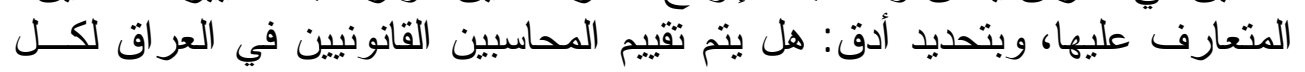

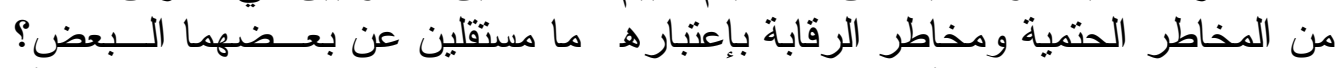

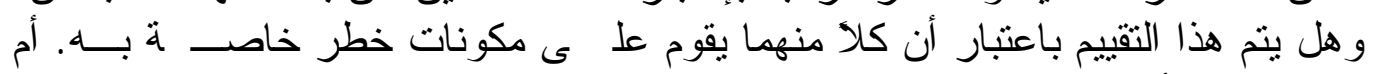

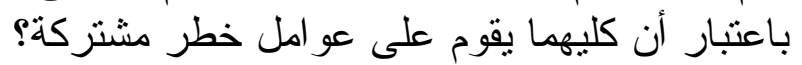

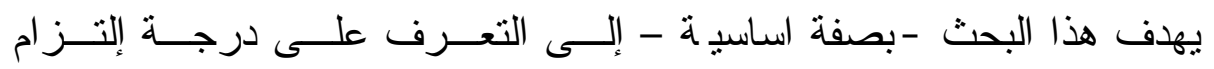

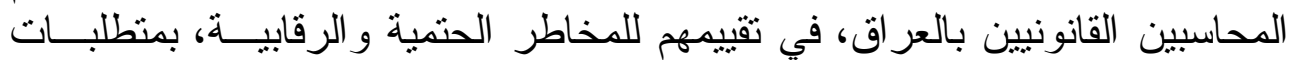

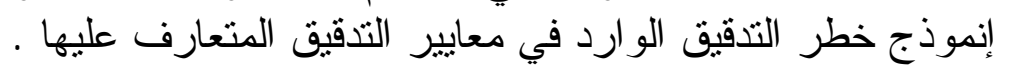

$$
\text { أهمية البحث أهمية البحث من المنطلق الآتي: }
$$

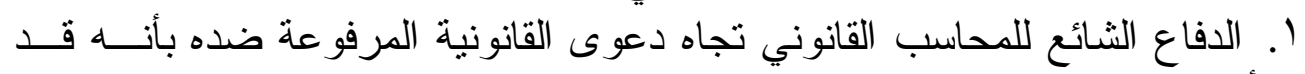

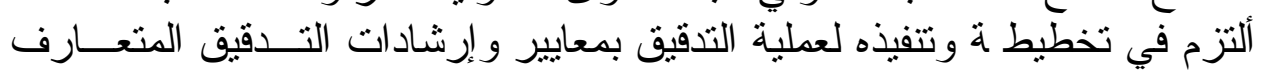
عليها.

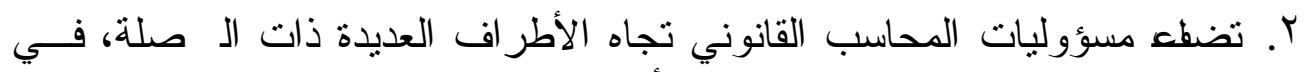

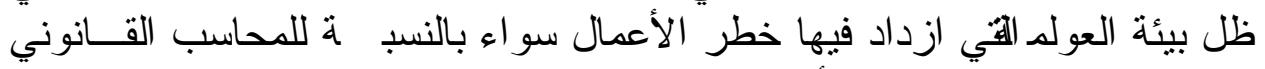

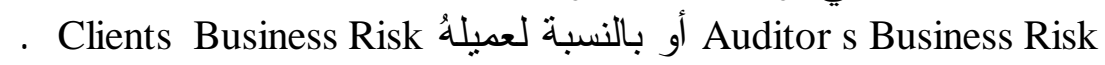

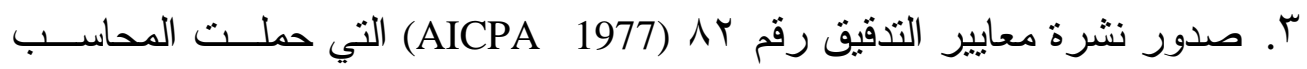
القانوني صر امة مسؤولية إكتشاف الغش في في القو ائم المالية.

خطة البحث

لتحقيق هدف البحث تم تبو يبهُ إلى الأقسام الآتية:

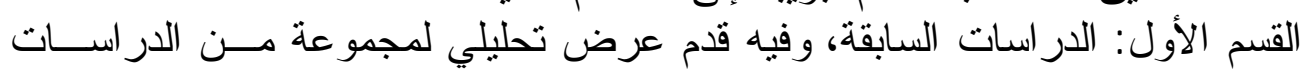
السابقة في موضو ع البحث. 
القسم الثاني:نهجية البحث وفيه يتم أثنتقا ق فروض البحث ، ثم استعر اض مجتمــع الار اسة ووسائل جمع البيانات.

القسم الثالث: تحليل البيانات و تفسيرها، وفيه يتت اســتعر اض سلــسلة الاختبـــار ات

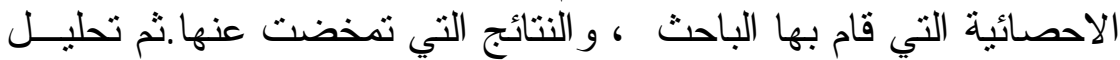

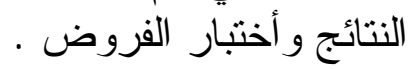

\section{القسم الأول \\ الار اســات السـابقة}

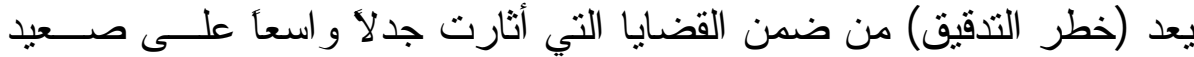

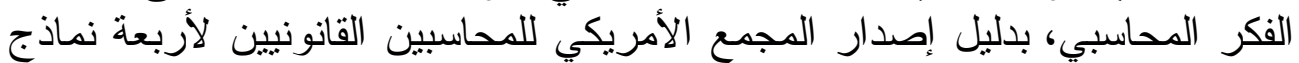

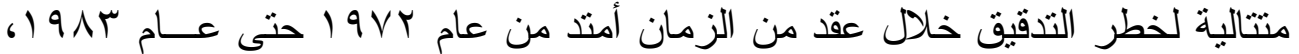

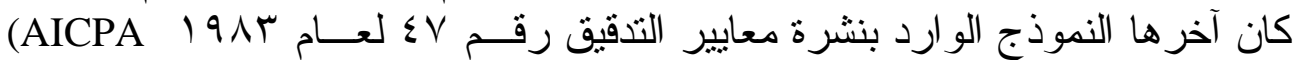

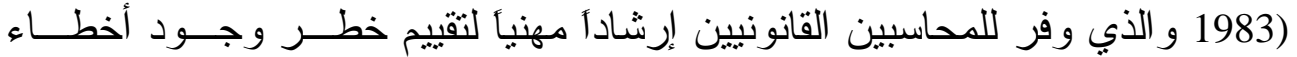
جوهرية في القوائم المالية.

في ذلك النموذج، نم التعامل مع مكونين من مكونات خطر التدقيق هما :

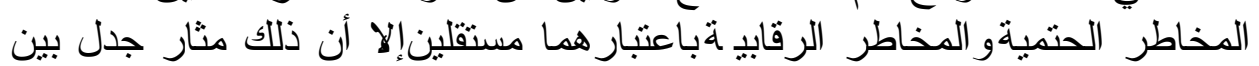

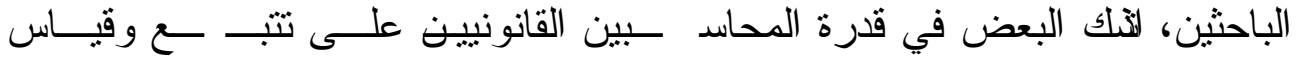

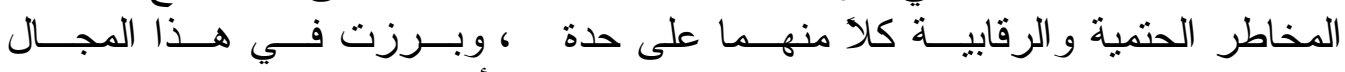
در اســــة (Cushing and Loeb beck, 1983) التي أثبتت وجود اعتماد منبادل يــتم

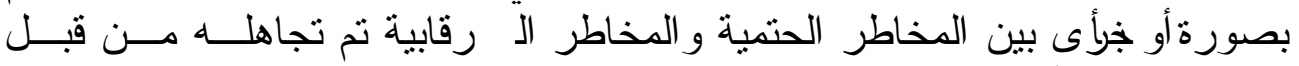
الإنموذج، كما أثنارت در اسة (Kinney 1989) ودر اســة Kreuzledtand and Wall)

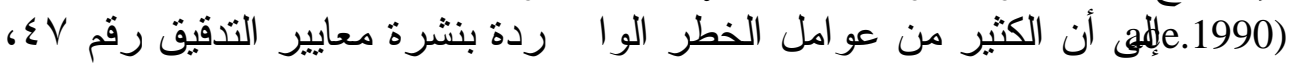

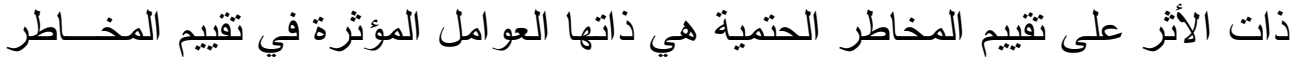

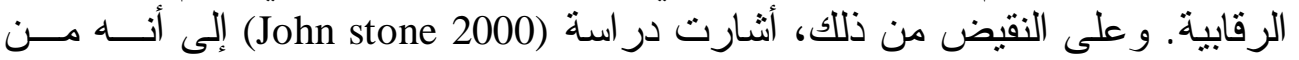

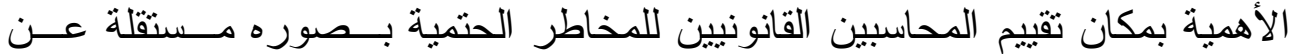

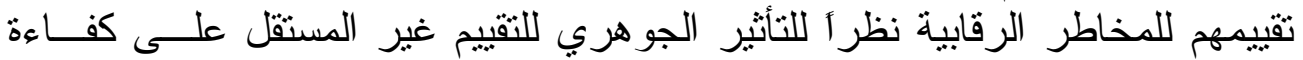
وفاعلية عملية التدقيق وللتدليل على ذلك أثنا رت الدر اسة إلى أنه في حالة إعطــاء

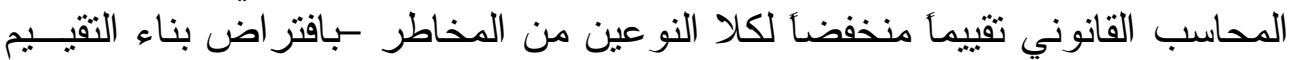

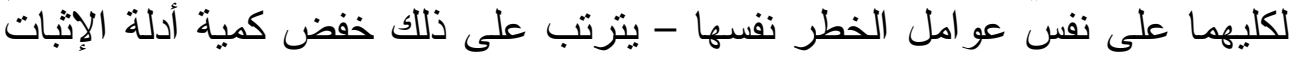

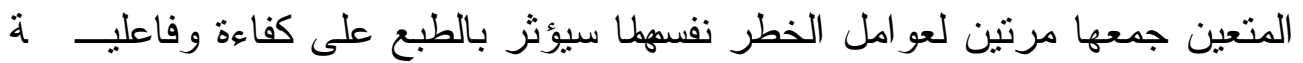

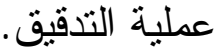

تعد الدر اسات السابقة التى تتاولت بالتحديد قضية أتساق أحكــام المحاســبين

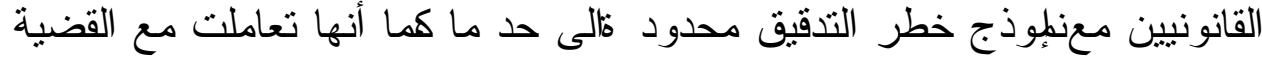

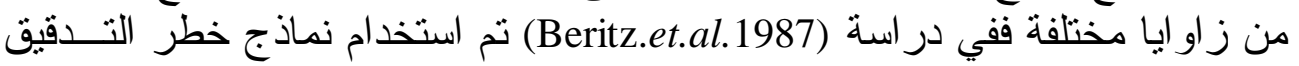

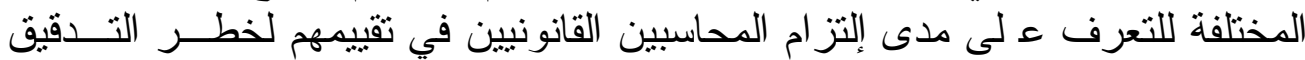


بمتطلبات تللك النماذج ،وقد أسفرت الدر اسدة عن نتيجة مؤداها عدم أتسـاق أحكــام

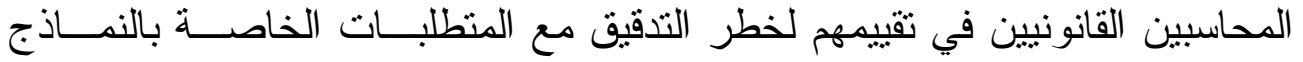

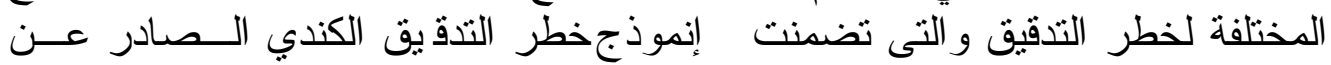

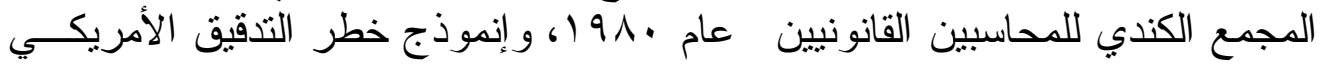

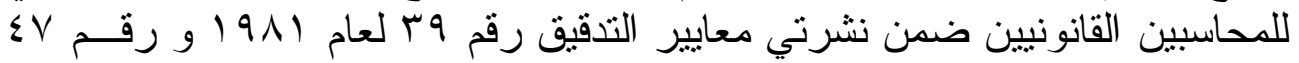

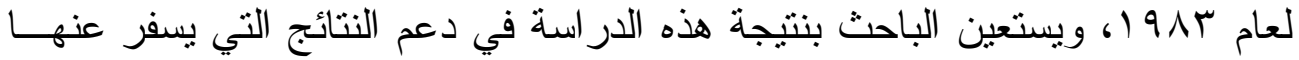

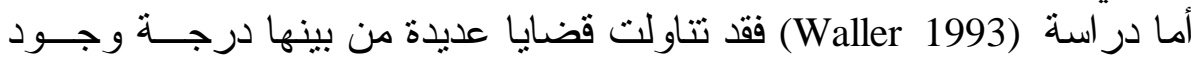
البحث الحام المالي. إرتباط إحصائي بين تقييم المحاسبين القانونيين لكل من المخاطر الحتمية و المخاطر

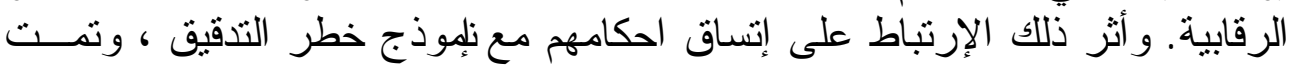

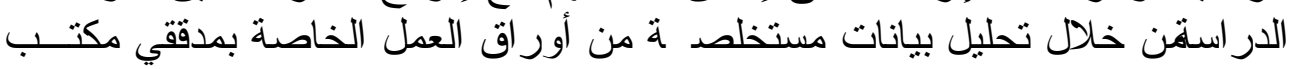

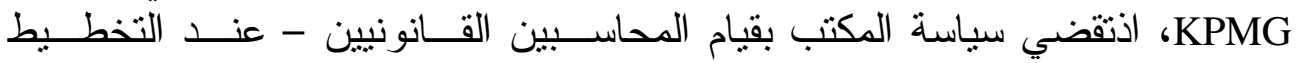

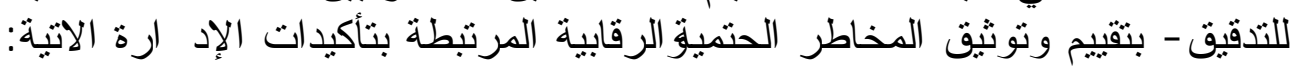

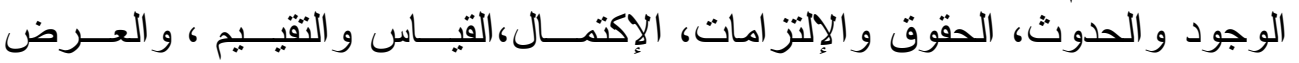
و الافصاح.

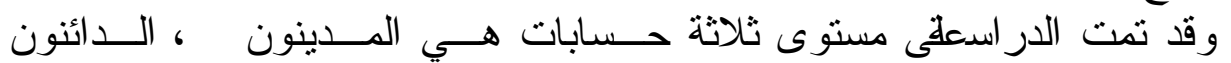

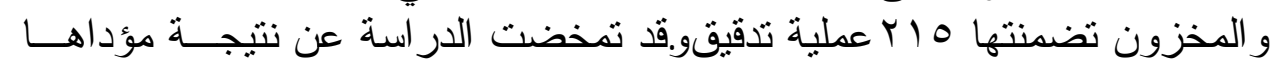

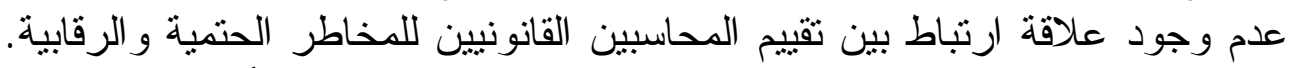

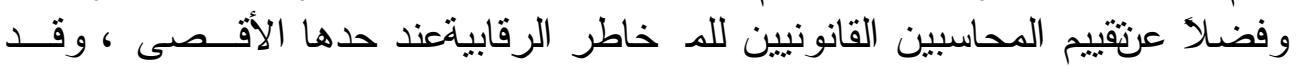

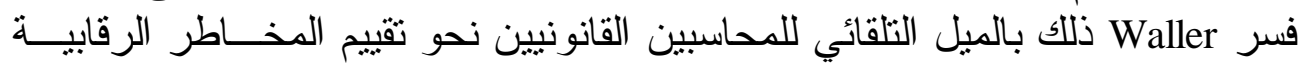

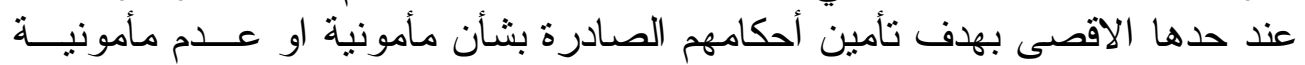

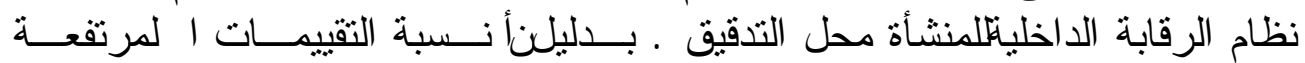

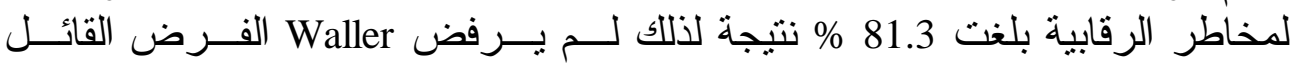
باستقلالية تقييم المحاسبين القانونيين لكل من المخاطر الحتمبية و المخاطر الرقابية.

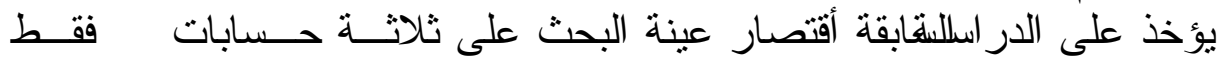

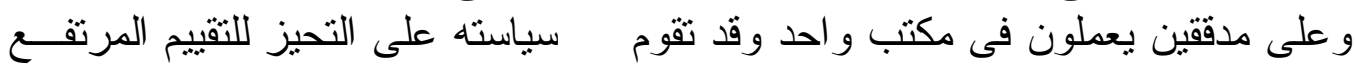

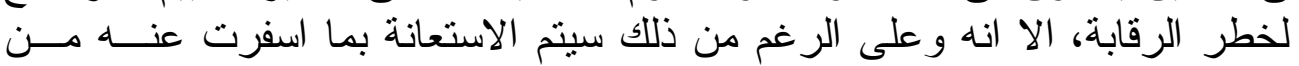

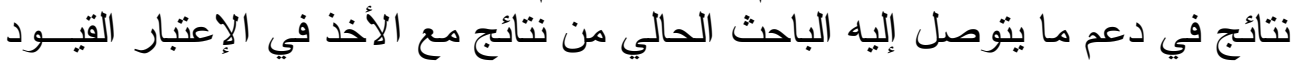

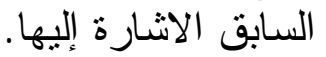

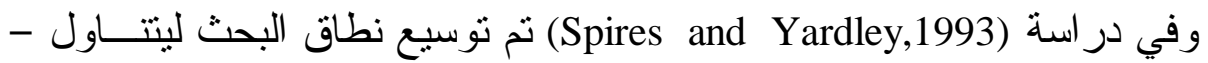

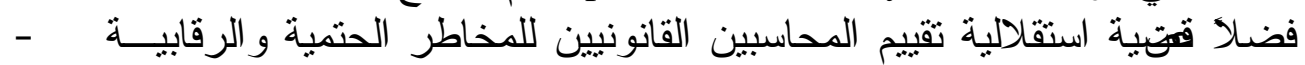

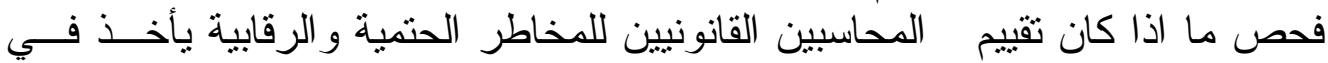

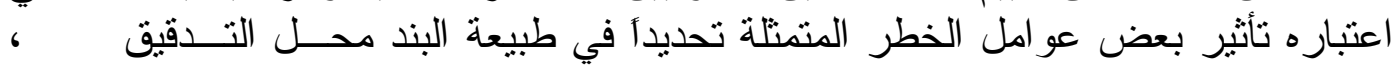

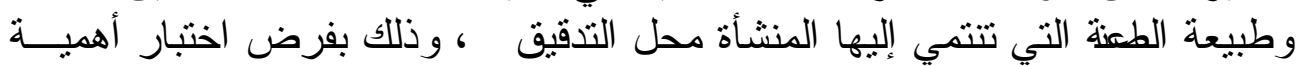

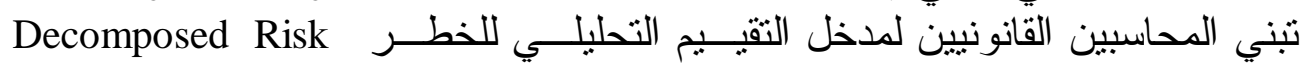




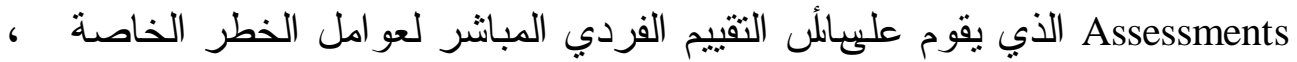

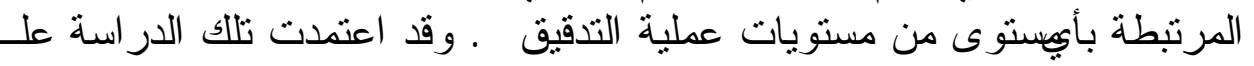

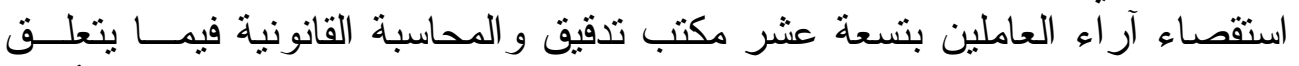

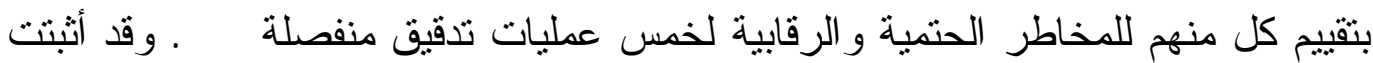

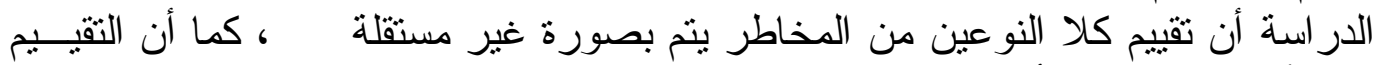

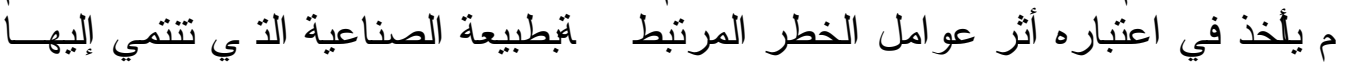
المنشأة تحت التدقيق.

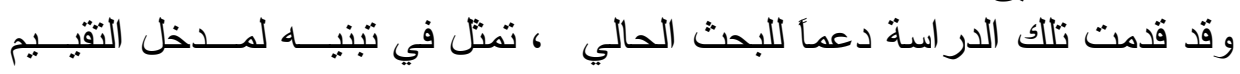

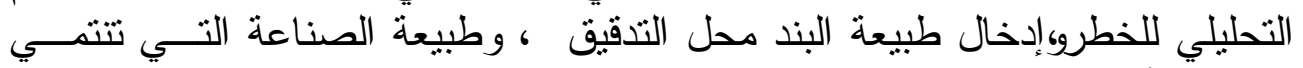

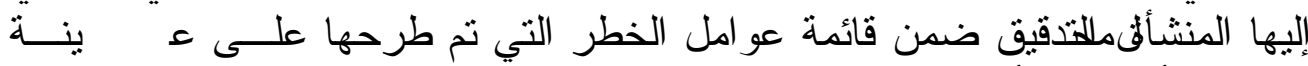

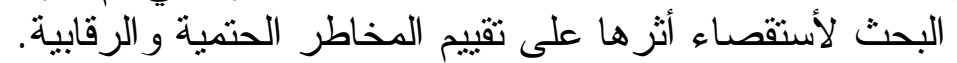

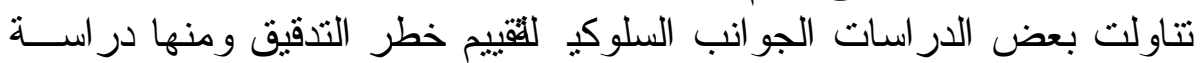
(Houston et.al 1999)

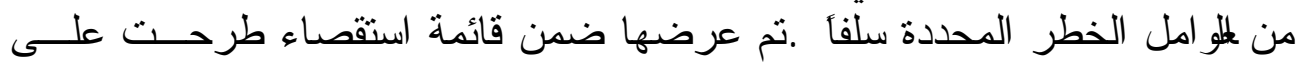

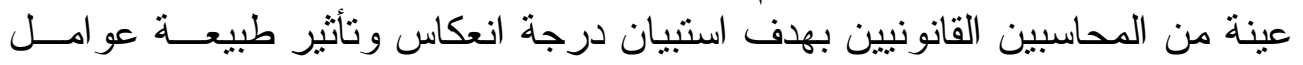

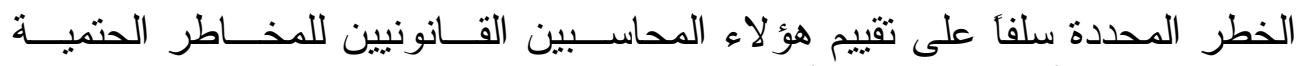

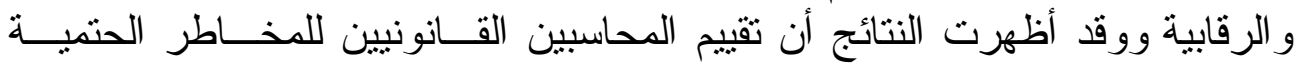

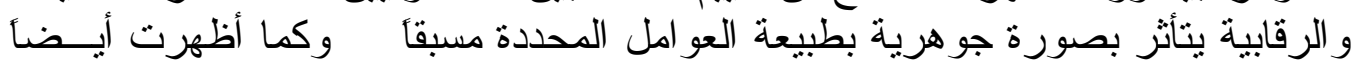

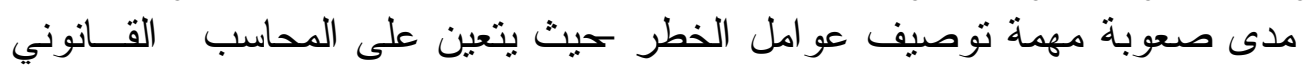

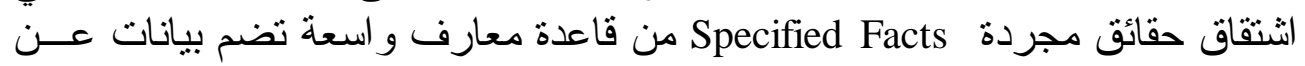

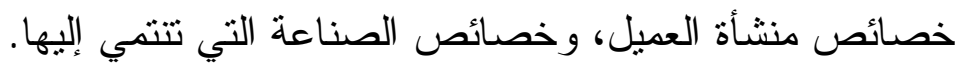

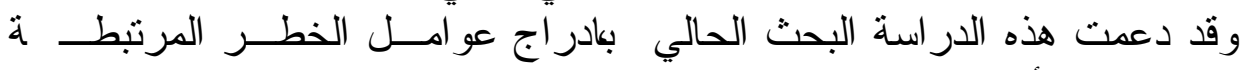

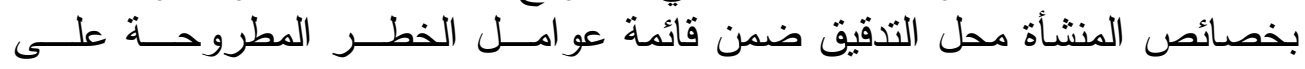

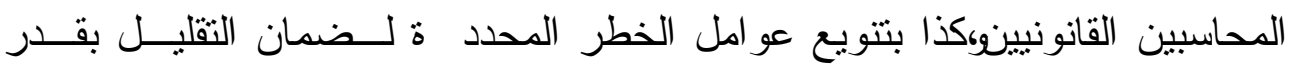

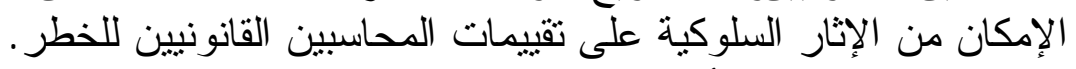

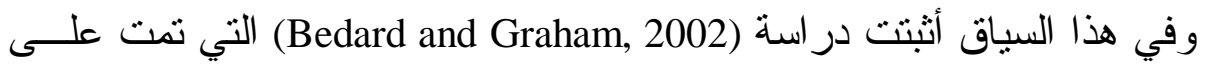

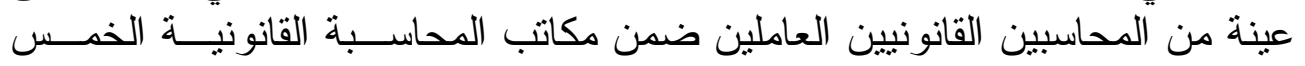

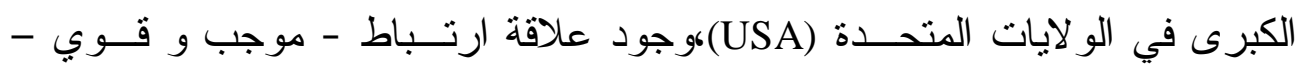

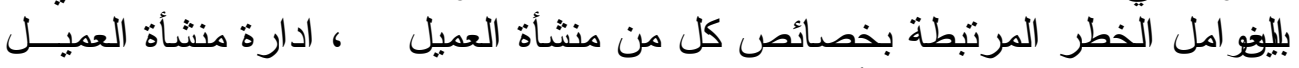

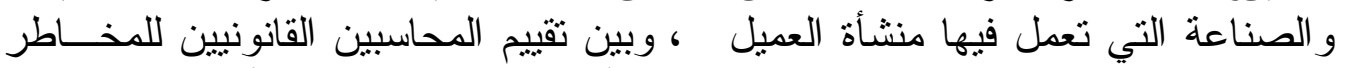

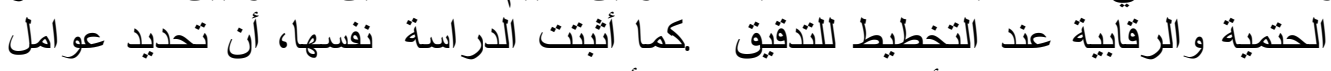

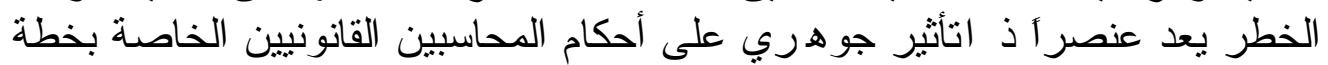
الإختبار ات الأساسية للتدقيق.

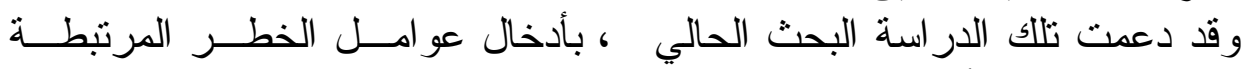

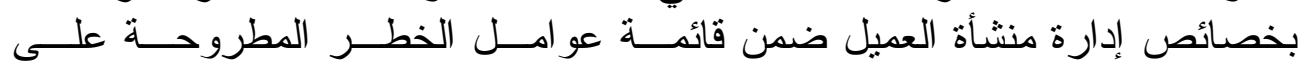


المحاسبين القانونيينلاستقصاء آر ائهم في درجة ت أثثر ها علــى تقيــيمهم للمخــاطر الحتمية و الرقابية.

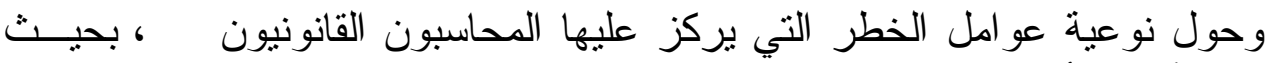

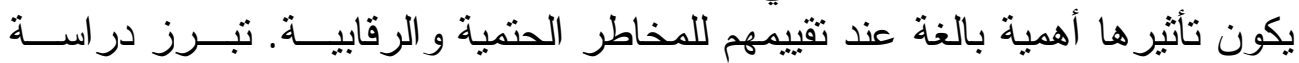
(Bedard and Graham, 1994)

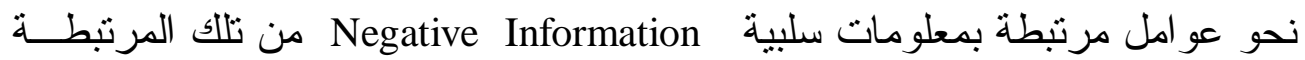

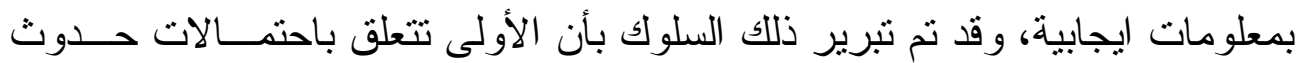

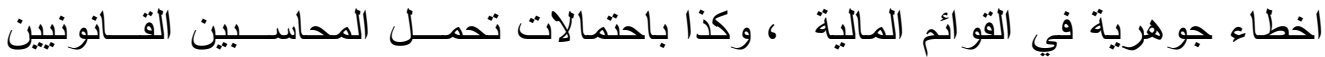

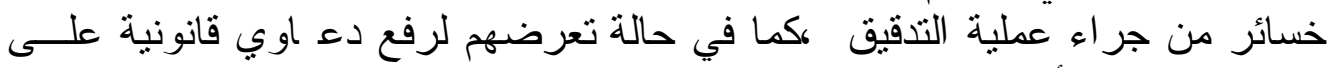

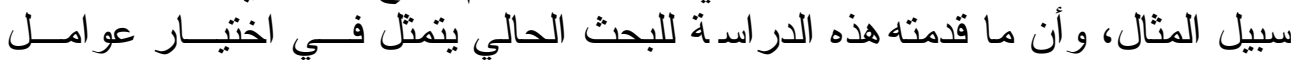

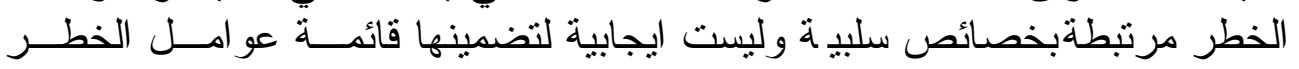

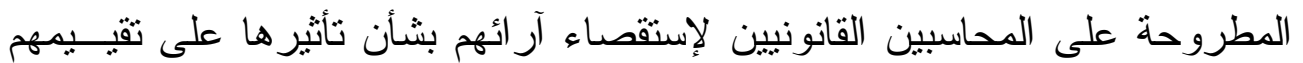
للمخاطر الحتمية و الرقابية. ومن تحليل نتائج الدر اسات السابقة يمكن الخروج بالماتهاتلاحظات الاتية:

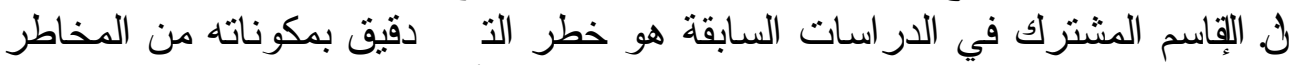

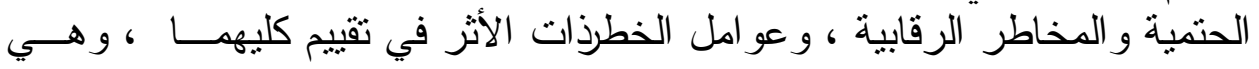

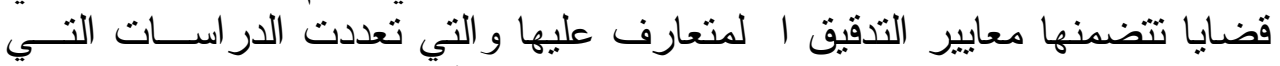

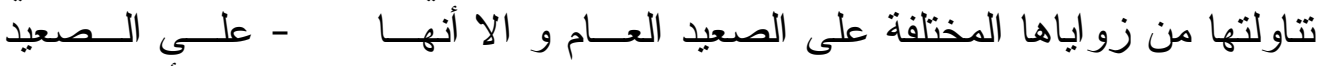

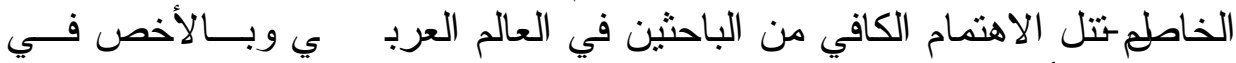

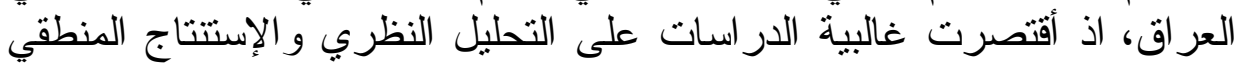

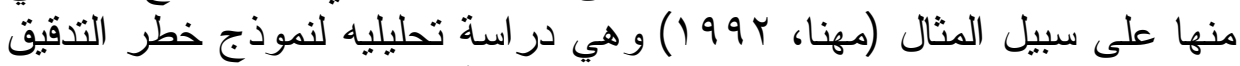

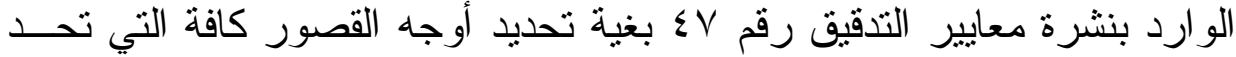

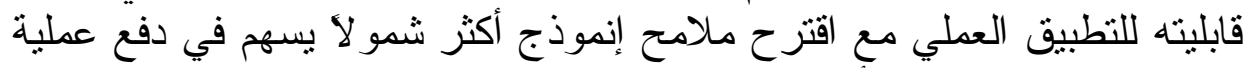

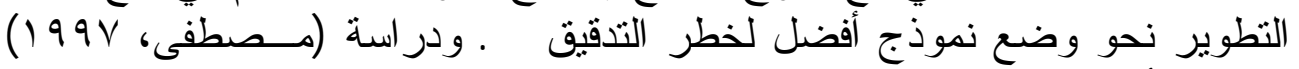

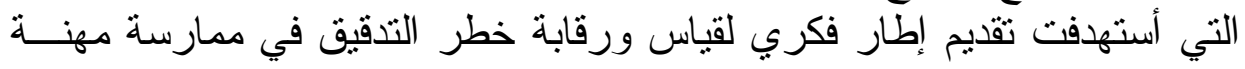

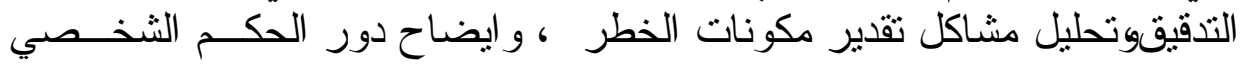

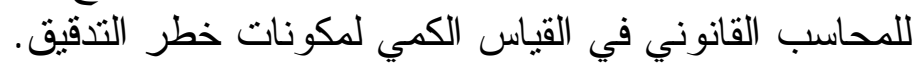

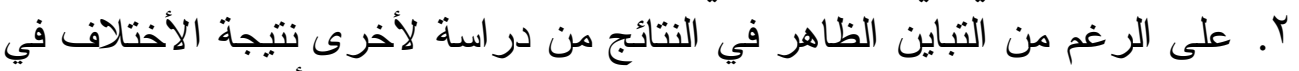

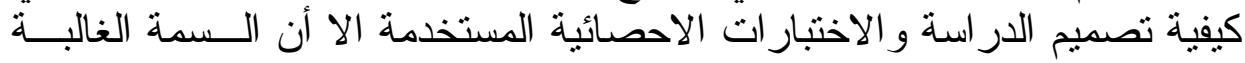

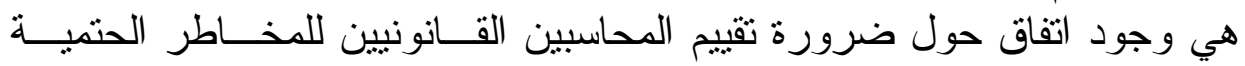

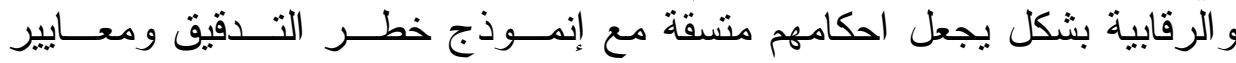

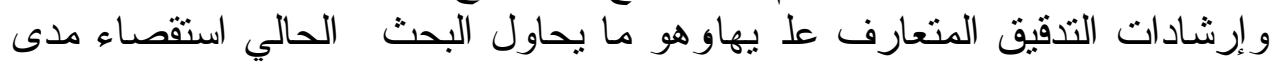


؟. وفرت الدر اسات السابقة اساساً جيداً يعتمد عليه الباحث في دعم منهجية البحــث

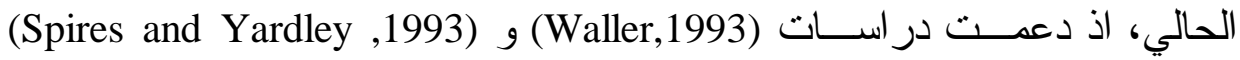

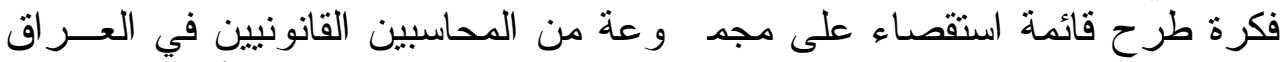

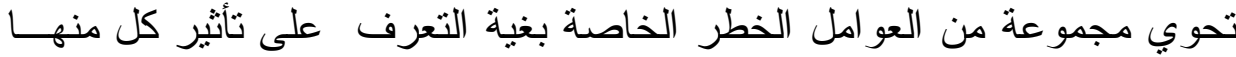

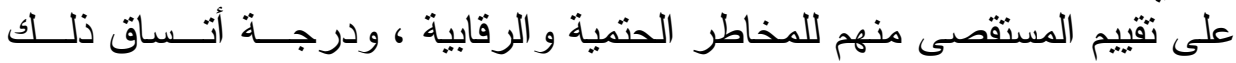
ومعايير التدقيق المتعارف غليه.

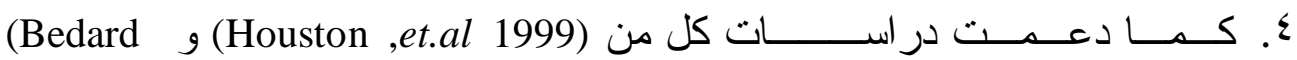

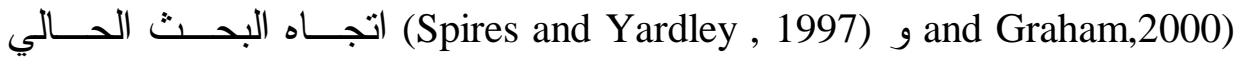

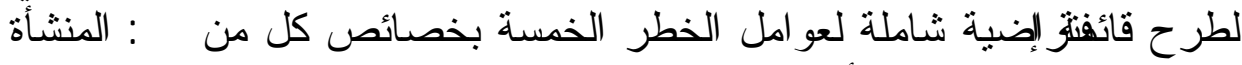

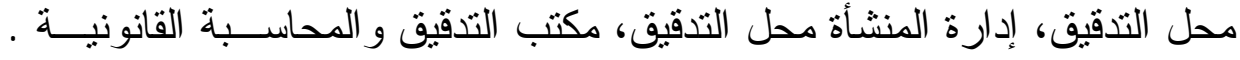

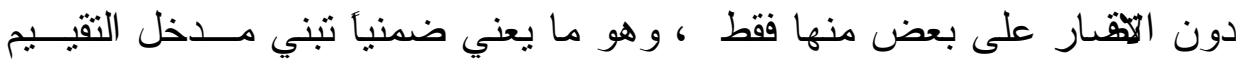
التحليلي للخطر التهل

๑. كذلك جعل الباحث من در اسة (Bedard and Graham,1994) أساسأ أرتكز عليــا

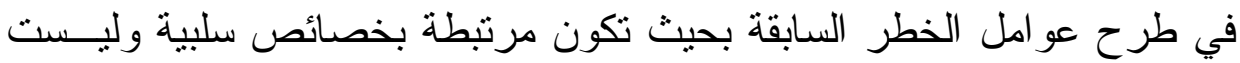
ايجابية وهو ما يتماثد ى و الاثار السلوكية الناتجة عن تعامل المحاسبين القانونيين مع خطر التدقيق وخطر الاعمال.

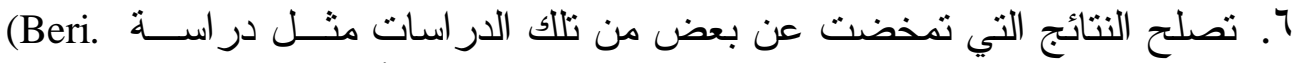

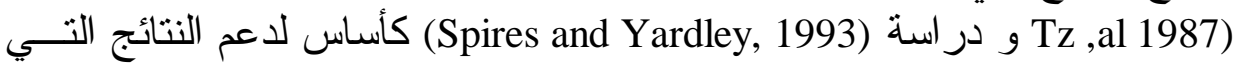

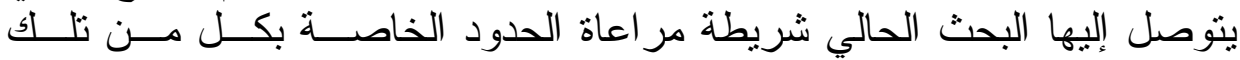
الدر اسات.

\section{منهجية البهم الثاني}

\section{أولاً - أشتقاق فرضية البحث}

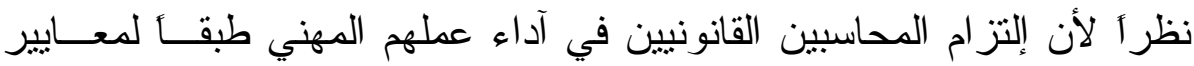

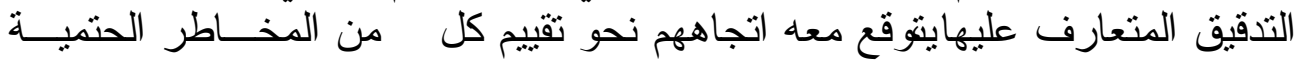

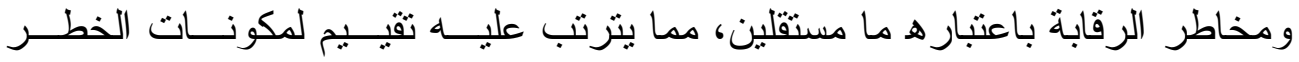

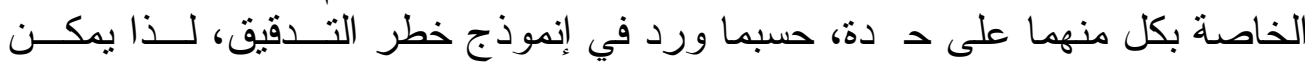

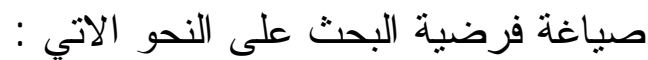

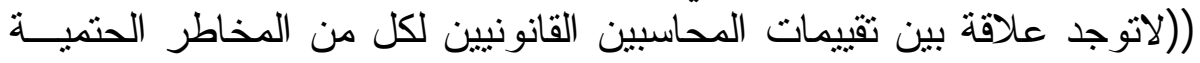

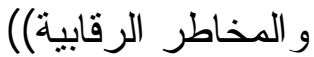

$$
\begin{aligned}
& \text { ثانياً - اسلوب البحث البه } \\
& \text { فيما يأتي عرض الئ الاسلوب المستخدم في البحث : } \\
& \text { أ. البيانات المطلوبة }
\end{aligned}
$$

تم تحديد البيانات المطلوبة بتصنيفها على مجمو عتين : 


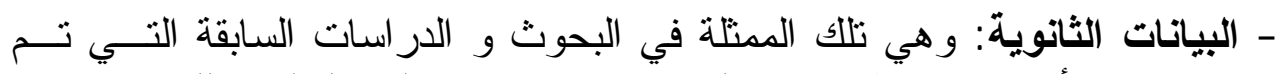

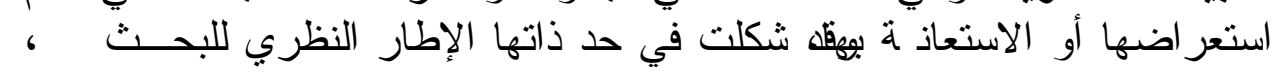

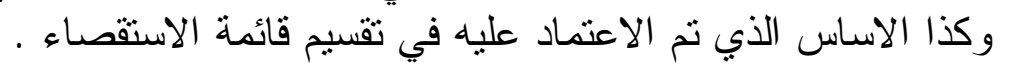

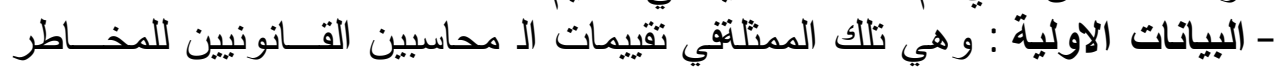

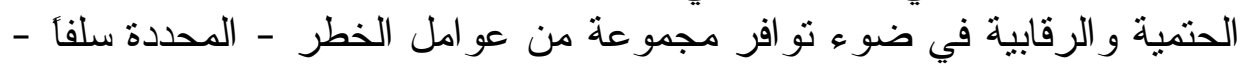

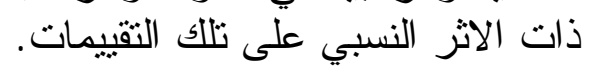

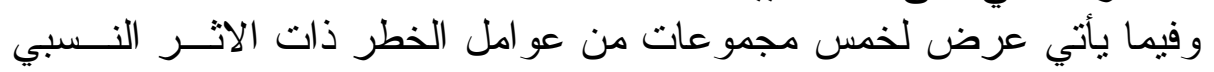

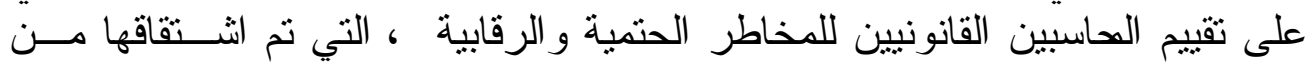

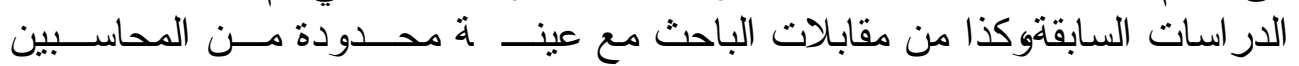

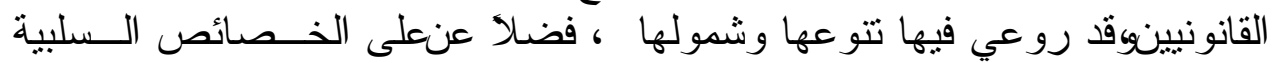
دون الايجابية.

\section{ا. . عوامل خطر مرتبطة بخصائص إدارة المنشأة محل التدقيق}

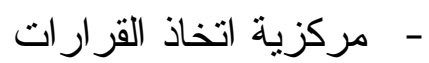

- المماطلة في تقديم تفسير تـ و اضحة للدحاسبين القانونيين ، أو عـدم الاســتجابة نهائياً. - ارتفاع معدل دور ان العمالة في مو اقع رئيسة، و لاسيما المحاسبين.

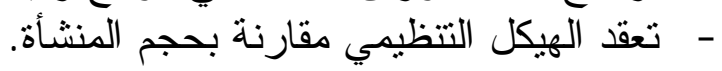

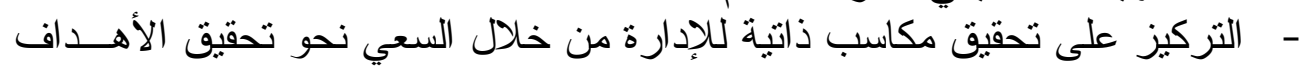
التي تحقق ذلك .

-القصور في نظرة الإدارة لأهمية الرقابة ، بلدليل عدم فاعلية الرقابة على الأنشطة

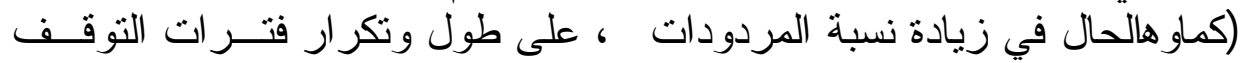

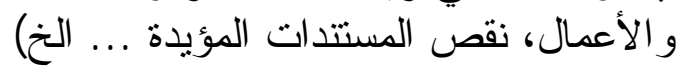
- وجود ضغوط على المحاسب القانوني لإنجاز عملية بعينة.

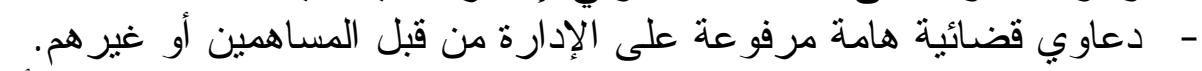

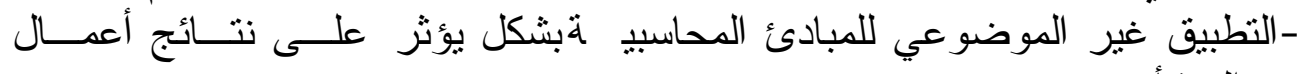
المنشأة.

- - تقيلهوك حول موثوقية التقدير ات المحاسبية نتيجة عدم تأهيل أو نقص خ برة

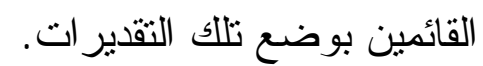
- عدم فاعلية السياسات و الإجر اءات الإدارية لتأمين البيانات و الأصول.

r. عوامل خطر مرتبطة بخصائص الصناعة التي تعمل فيها المنشأة محل التدقيق

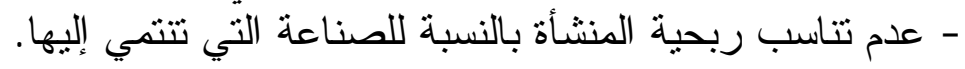
- ارتفاع درجة حساسية نتائج النشاط للظروف لألفية الإقتصادية المحيطة. 
- ارتفاع معدل التطور التكنولوجي في الصناعة التي تتنمي إلبها المنشأة.

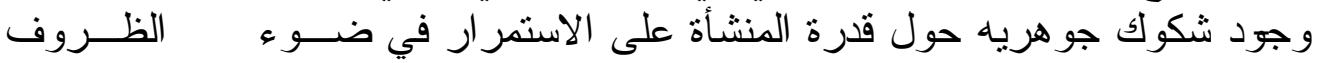

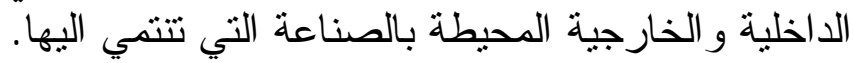

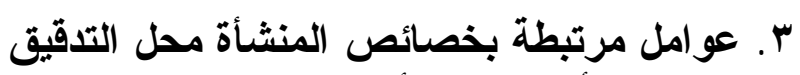

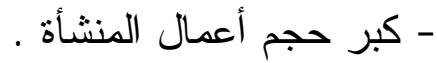
- تعقيد الثكل القانوني للمنشأة .

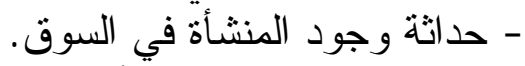

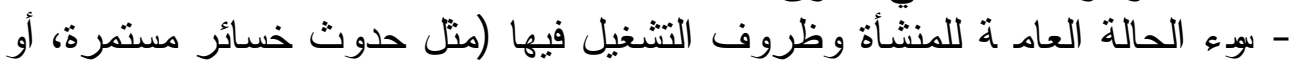

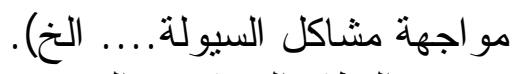
- ضعف النظام المحاسبي المستخدملن حيث الطرق و و السجلا ت ت المستخدمة فـي

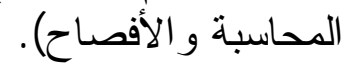
- ضعف البيئة الرقابية للمنـشأة (مــن حيــث الـــياسات و الاجــر اءات الرقابيــة (المستخدمة).

ع. عوامل خطر مرتبطة بخصائص عملية التدقيق

- و وجود العديد من المعالجات المحاسبية المعقدة أو الثائكة.

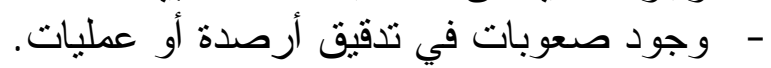

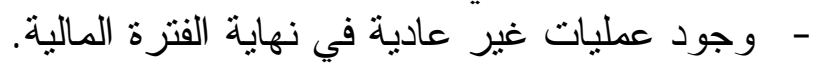
- كبر حجم الاخطاء المكتشفة خلادل تدقيق الفترة المالية السابقة .

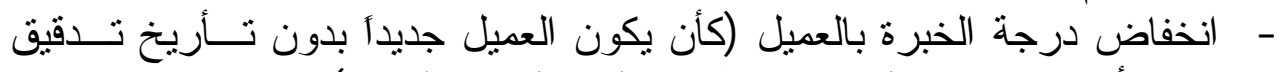

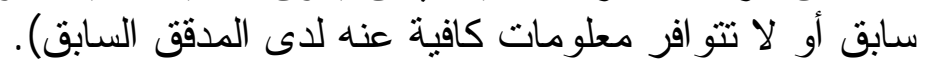

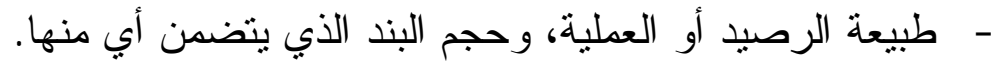

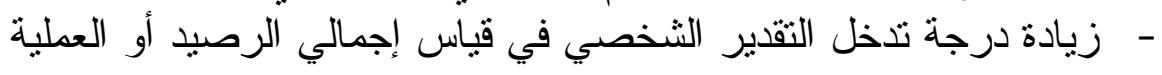

ه. عوامل خطر مرتبطة بخصائص مكتب التدقيق والمحاسبة القانونية

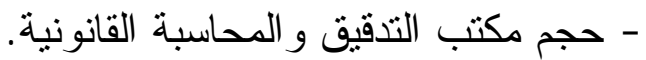

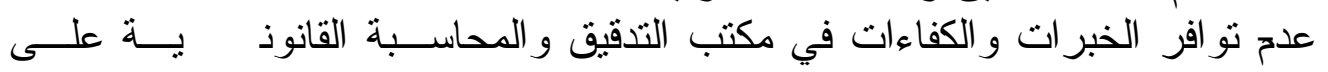
المستويات كافة. - السياسة العامة لمكتب التدقيق و المحاسبة القانونية.

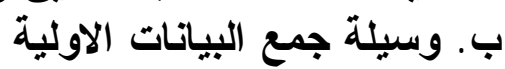

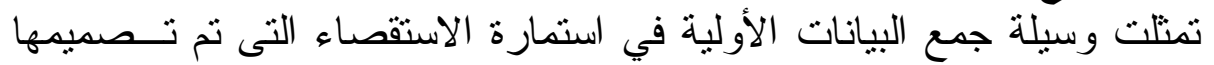

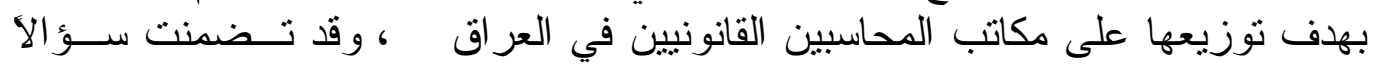

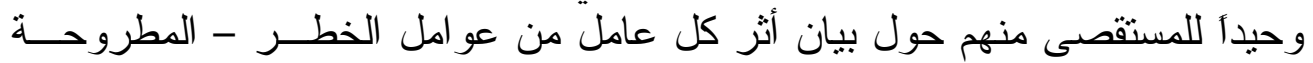

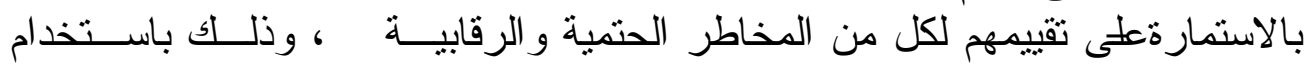


اسلوب الأوزان المدرجة للخطر النسبي التي يوليها المستقصى منهم لكل عامل مــن

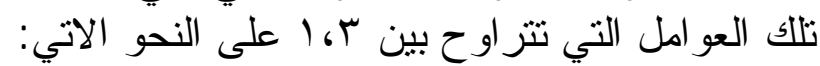

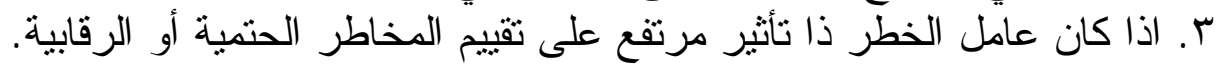

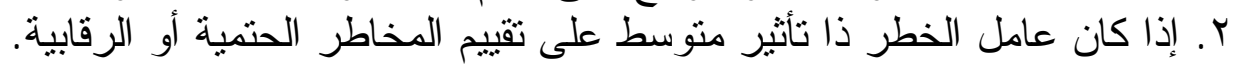

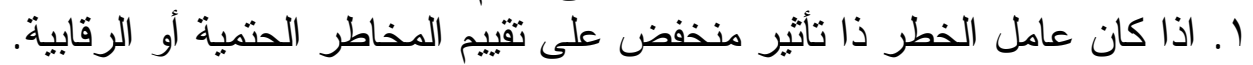

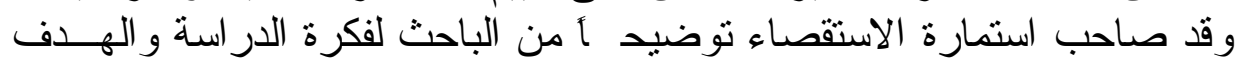

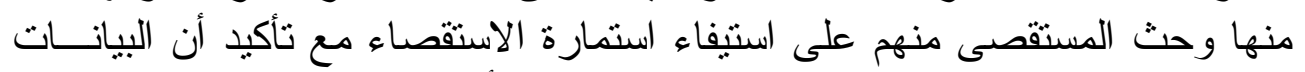

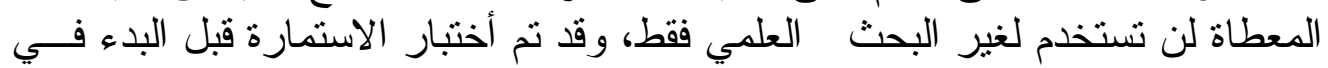

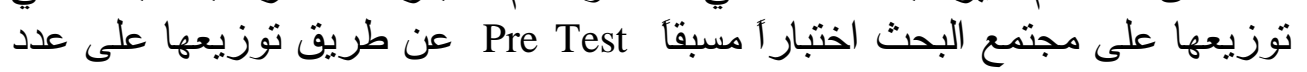

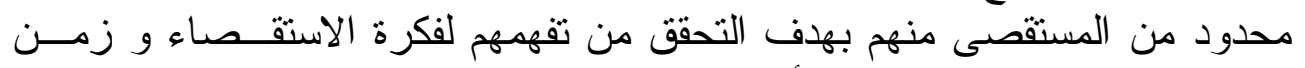

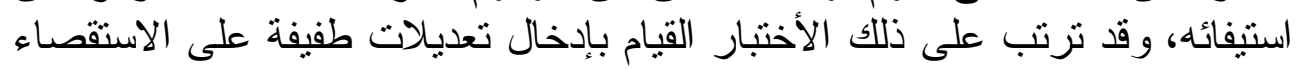

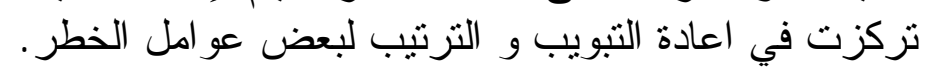

ت. مجتمع البحث وعن اعة التينته

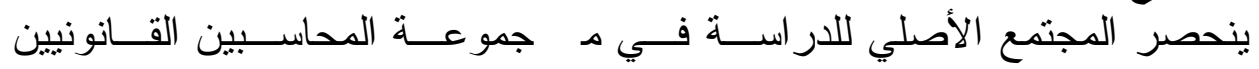

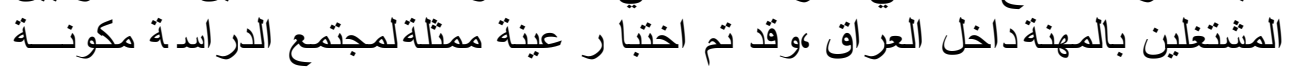

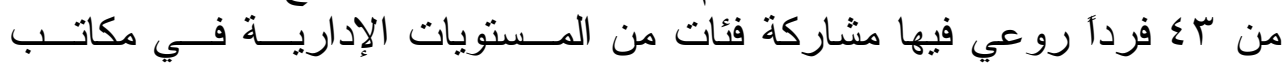

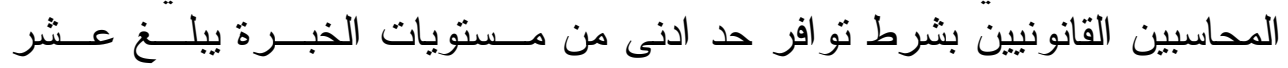

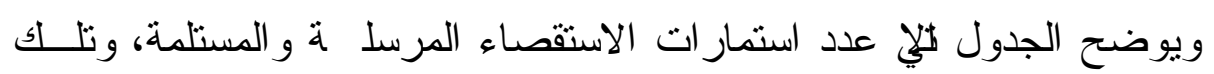
سنو ات . التي أجري عليها التحليل:

\section{الجدول المدا \\ عينة اللدراسة}

\begin{tabular}{|c|c|c|c|c|c|}
\hline \multicolumn{2}{|c|}{ عدد الاستمارات التي تم } & \multicolumn{2}{|c|}{ عدد الاستمارات المستلمة } & \multicolumn{2}{|c|}{ عدد الاستمارات المرسلة } \\
\hline النسبة\%\% & العدد & النسبة\%\% & العدد & النسبة \% & العدد \\
\hline \%४ $\varepsilon$ & Tr & \%VV & r & $\%$ & $\varepsilon r$ \\
\hline
\end{tabular}

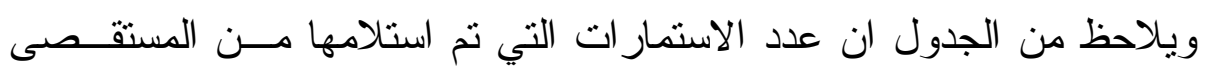

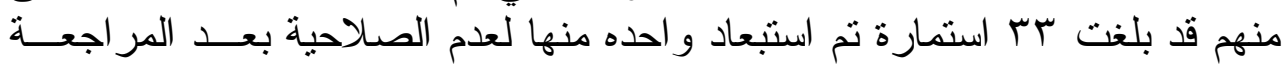

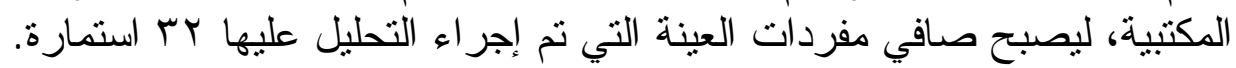

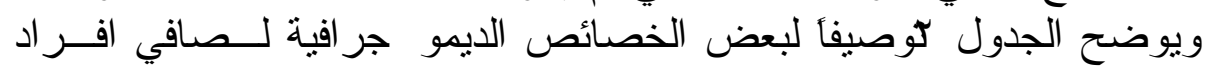
العينة التي تم جمع البيانات منها. 


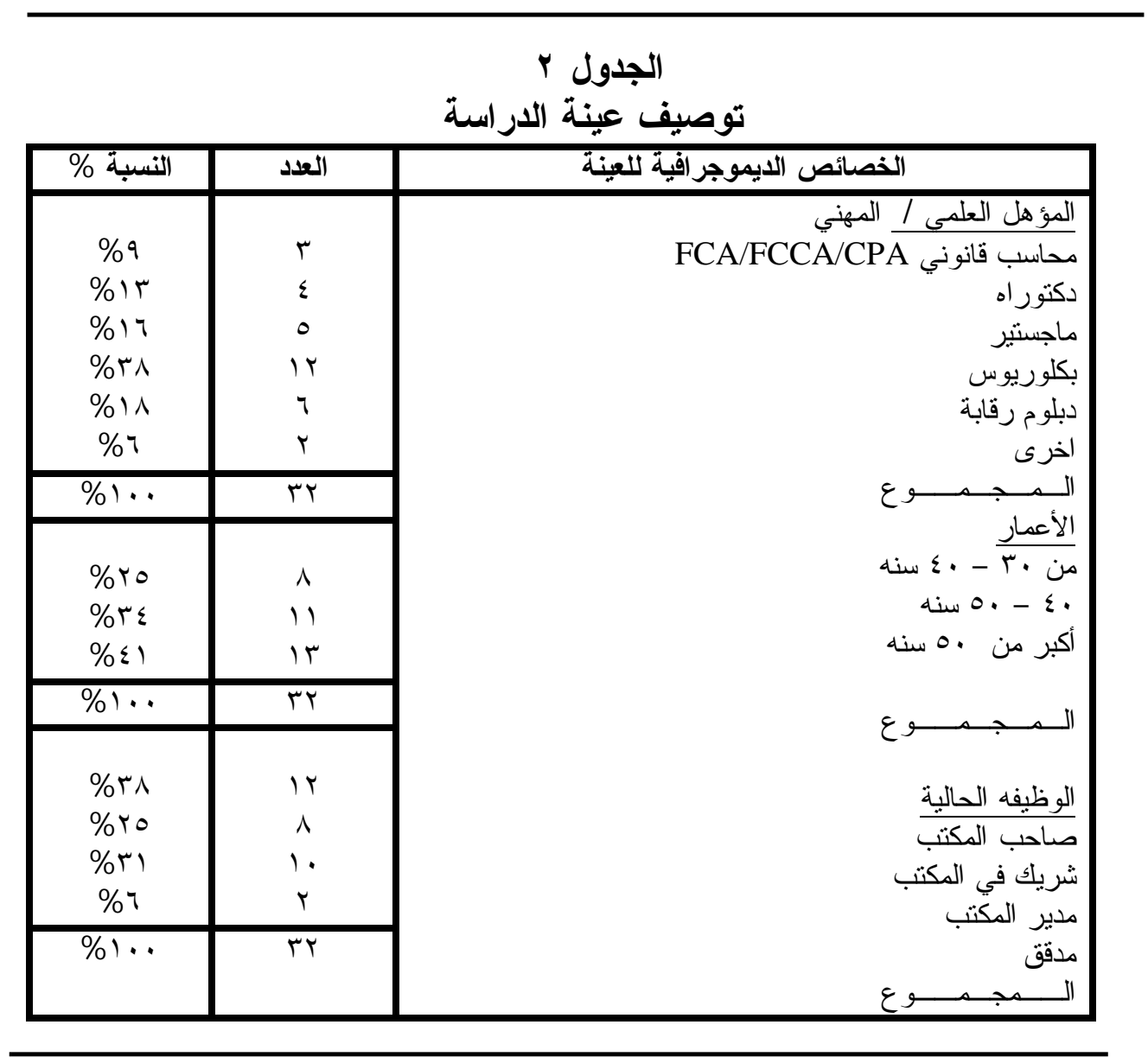

\section{القسم الثالث \\ تحليل البيانات و تفسيرها}

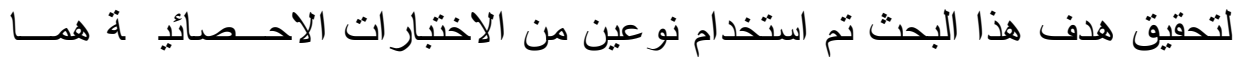

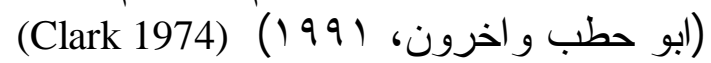

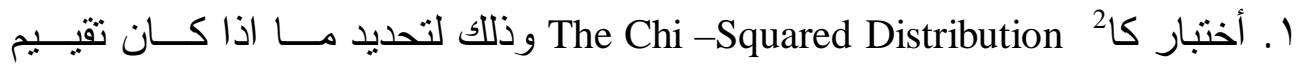

المحاسبين القانونيين في العراق لكل من المخاطر الحتمية و المخاطر الرقابيــة

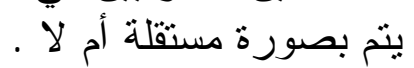

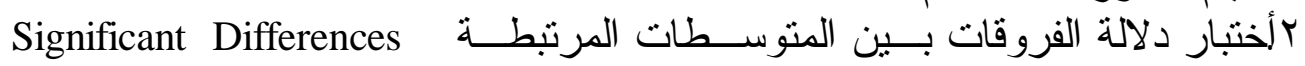
Between Correlated Means ، وذللك للتعرف على درجة الخطر النسبي التـي لتئي يوليها المحاسبين القانونيين في العر اق لعوامل الخطر المؤثزة على تقييم كل من لئري المخاطر الحتمية و المخاطر الرقابية. وفيما يأي استعر اض موجز لنتائج تللك الاختبار ات: 


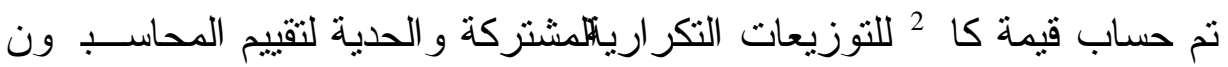
أختبار كا2

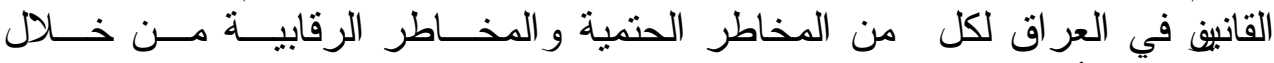

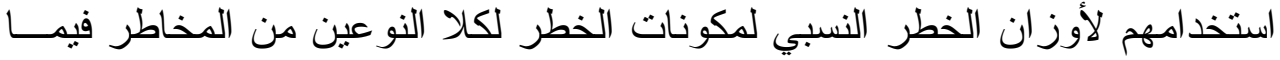

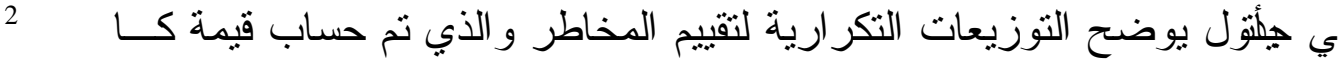
على اساسـ

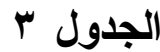

التوزيعات التكرارية المشتركة و الحدية لتقييمات المخاطر الحتمية و الرقابية

\begin{tabular}{|c|c|c|c|c|}
\hline اجمالي & منخفضابة & متاطرة & مخاطرة & بـــــــــــان \\
\hline 448 & 32 & 32 & 384 & مخاطر حتمبية مر تفعــــة \\
\hline 352 & 32 & 96 & 224 & مخاطر حتمية متوسطــة \\
\hline 192 & 96 & صفر & 96 & مخاطر حتمية منخفضة \\
\hline 992 & 160 & 128 & 704 & اجــــال \\
\hline
\end{tabular}

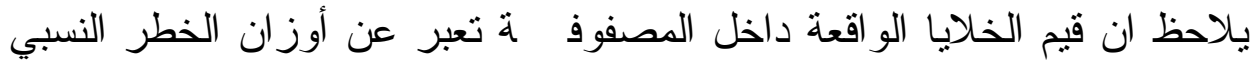

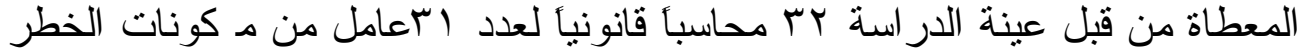

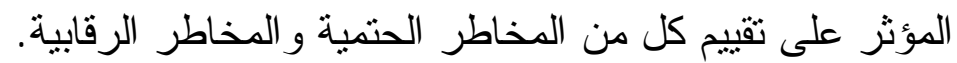

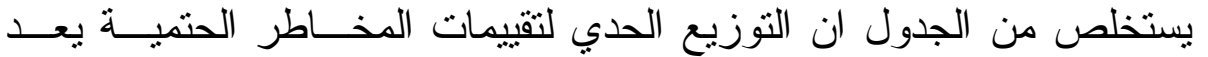

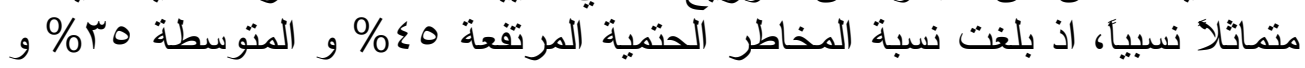

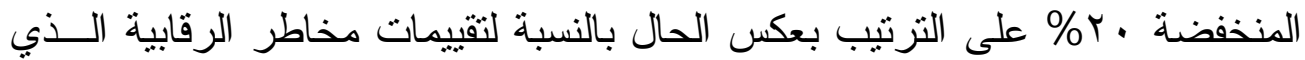

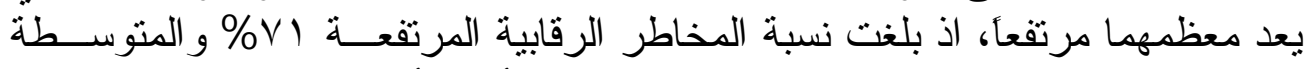

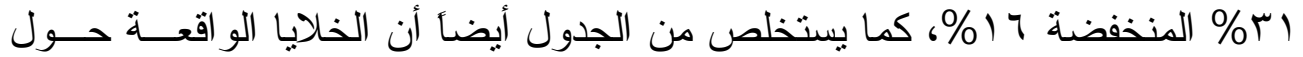

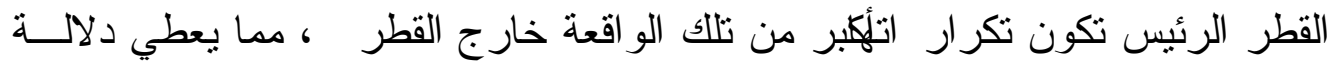
لعدم استقلال تقييمات المحاسبين القانونيين في العر اق للمخاطر الحتمية و المخــاطر الر قابية.

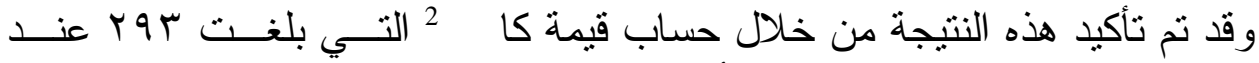

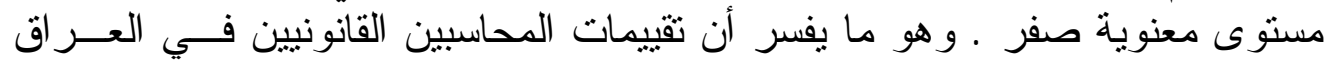
لكل من المخاطر الحتمية و مخاطر الرقابية ليست مستقلة ، وهو ما يدعو الباحث إلى رفض فرض البحث. 
أختبار دلالة الفروقات بين المتوسطات المرتبطة

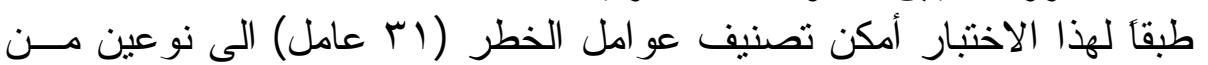

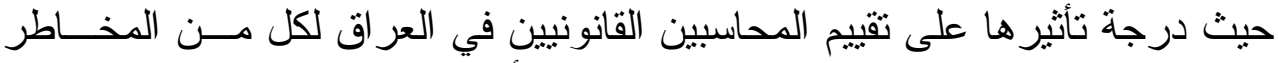

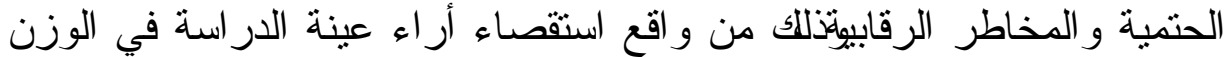

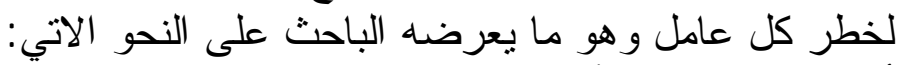

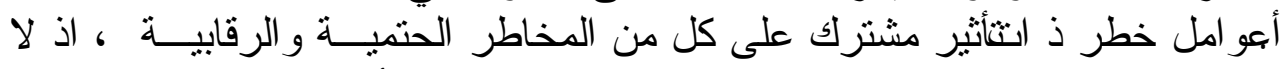

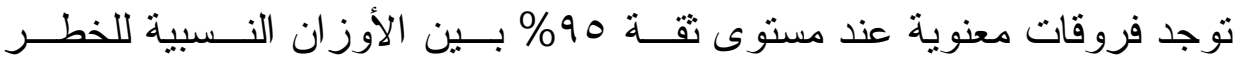

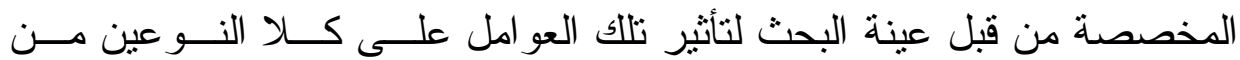

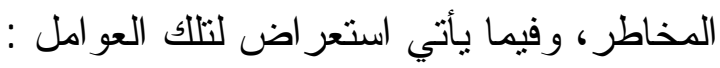

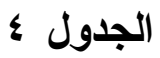

عوامل الخطر ذات التأثثر على تقييم كل من المخاطر الحتمية والرقابية

\begin{tabular}{|c|c|c|c|c|c|c|c|}
\hline \multicolumn{6}{|c|}{ الأوزان النسبية للخطر } & \multirow{3}{*}{ عوامل الخطر } & \multirow{3}{*}{ r } \\
\hline \multicolumn{3}{|c|}{ المخاطر الرقابية } & \multicolumn{3}{|c|}{ المخاطر الحتمية: } & & \\
\hline منخفض 1 & متوسط & مرتفع 3 & منخفض 1 & متوسط & مرتفع & & \\
\hline I & / & $\begin{array}{l}1 \\
1 \\
1 \\
1 \\
1\end{array}$ & I & l & $\begin{array}{l}1 \\
1 \\
1 \\
1 \\
1\end{array}$ & 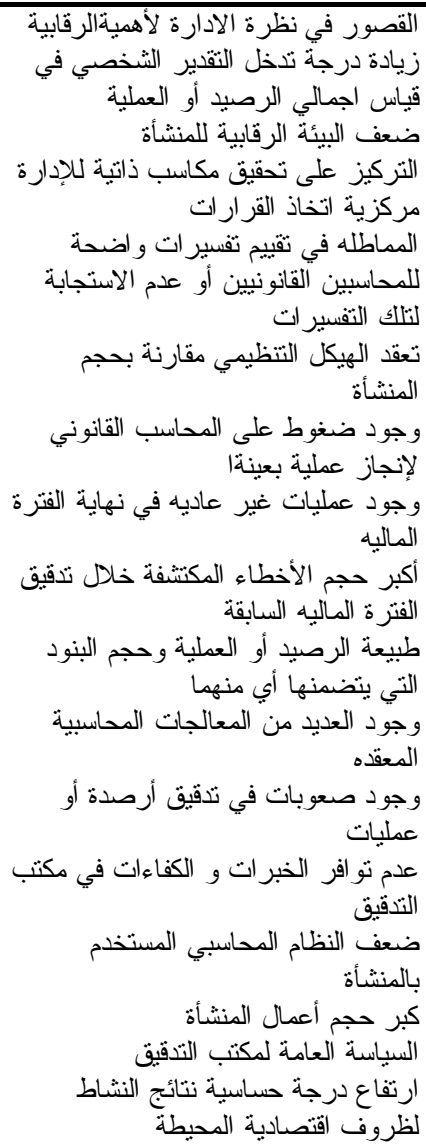 & $\begin{array}{l}1 \\
r \\
r \\
\varepsilon \\
0 \\
7 \\
V \\
1 \\
9 \\
10 \\
11 \\
14 \\
14 \\
18 \\
10 \\
11 \\
11\end{array}$ \\
\hline
\end{tabular}


هوبامل خطر ذات تأثير متباين على كل مــن المخــ اطر الحتميـة و المخــاطر الرقابية

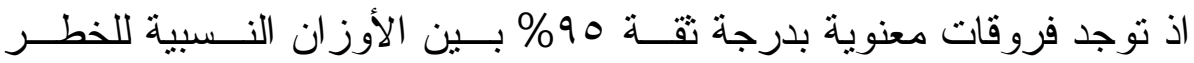

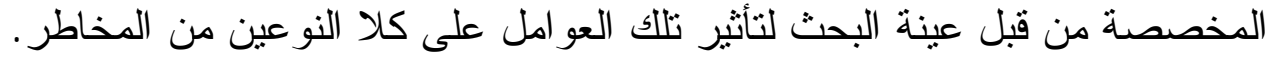

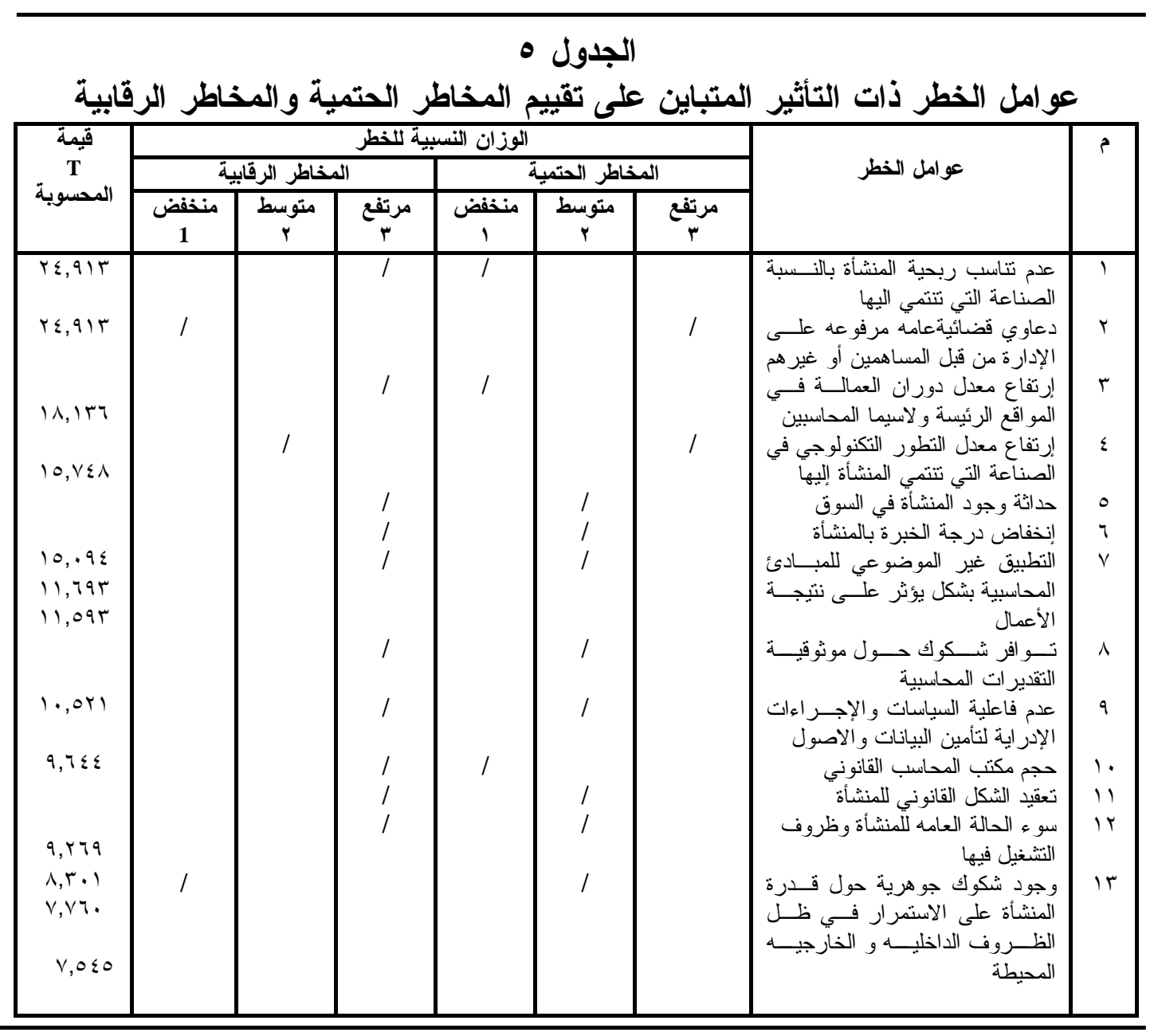

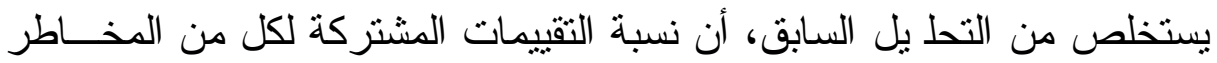

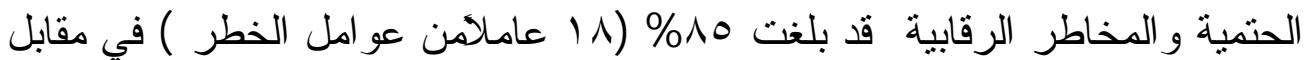

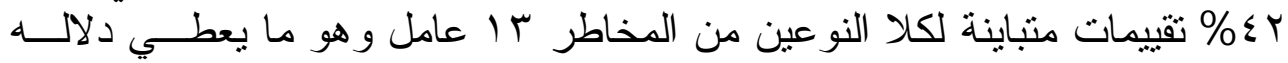

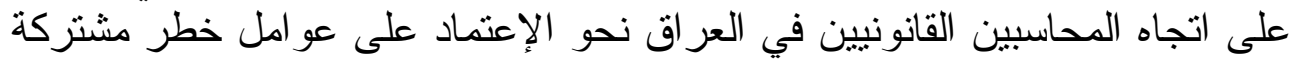

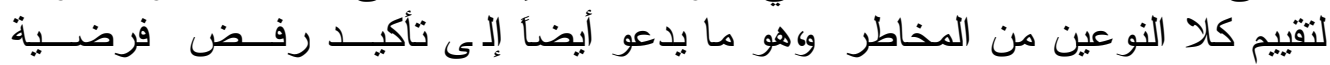




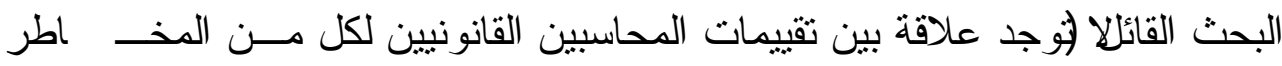
الحتمية و المخاطر الرقابية).

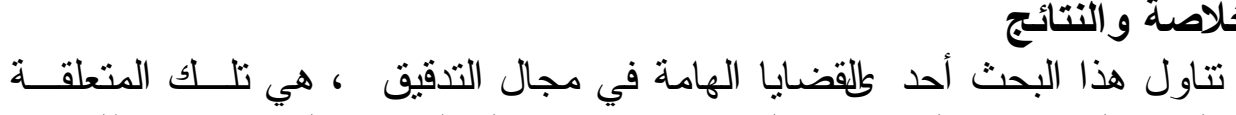

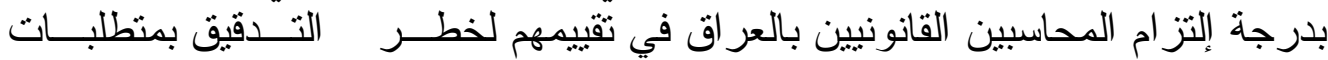

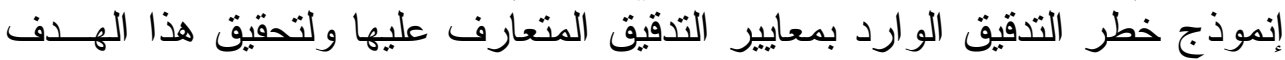

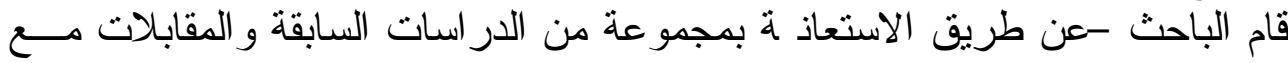

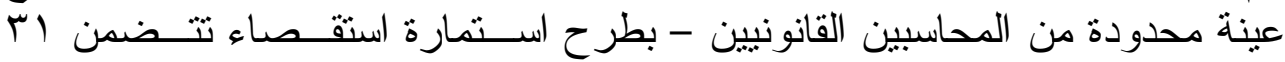

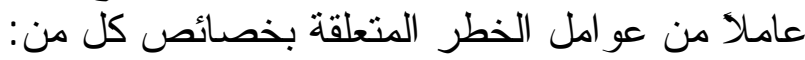

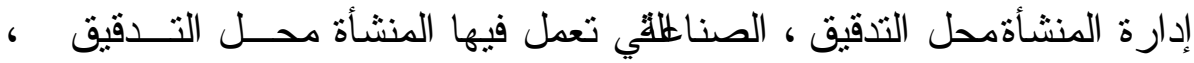

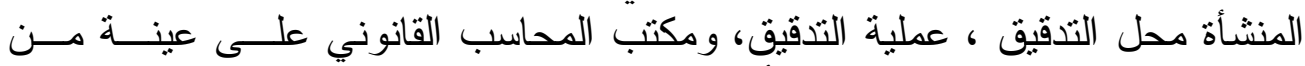

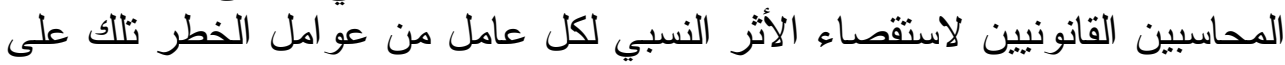

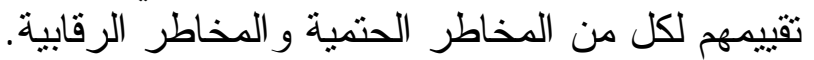

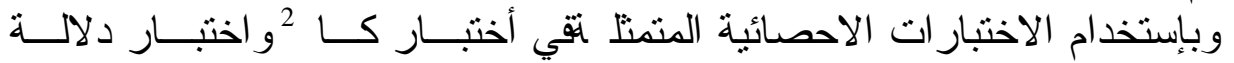

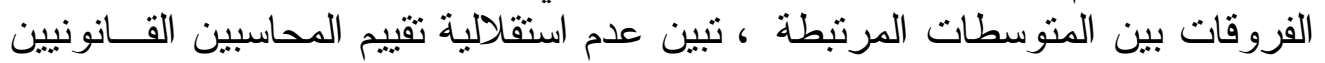

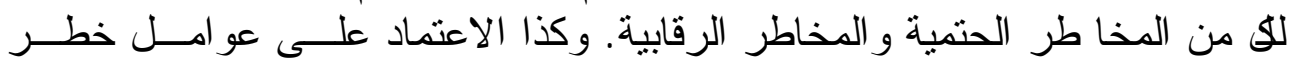

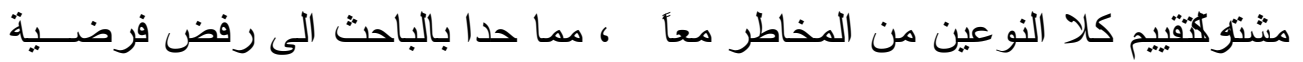

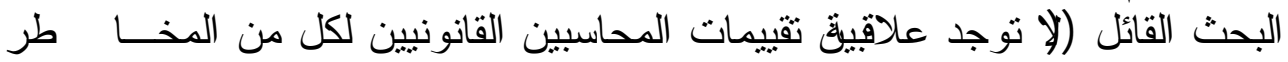

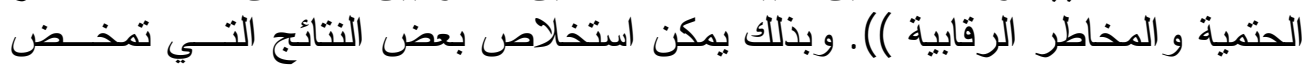

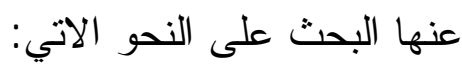
ا.عدم التز ام المحاسبين القانونيين في العراقي بأحكام نموذج خطر التدقيق بصورة

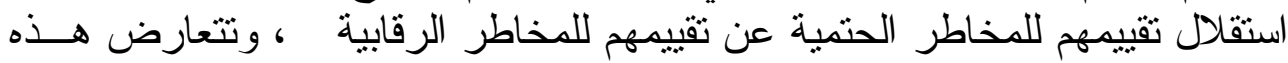

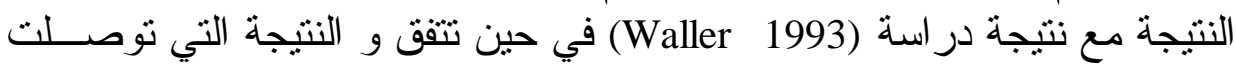
اليها در اسة (Beritze.al 1987) ودر اسة (1993 (Spires and Yardley 1993) .

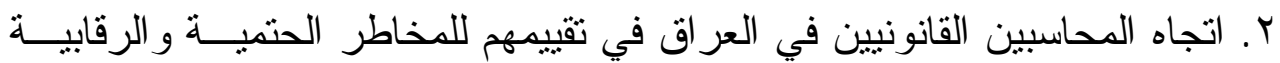

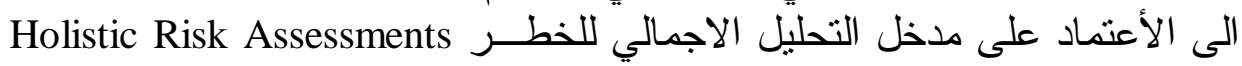

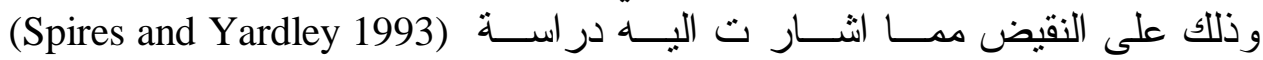

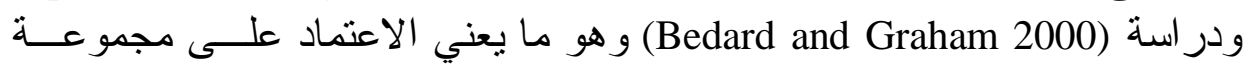

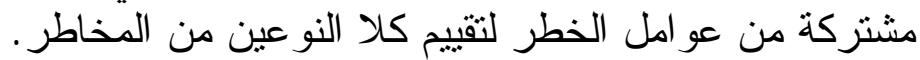

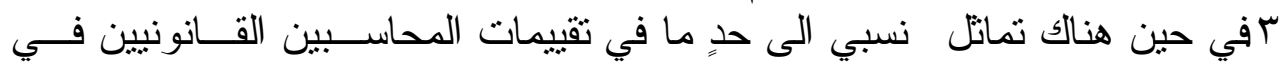

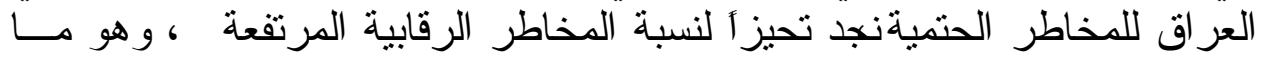

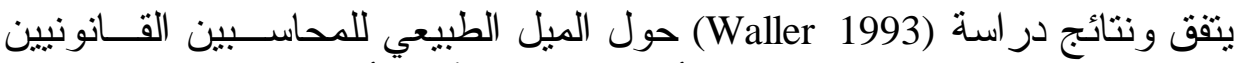

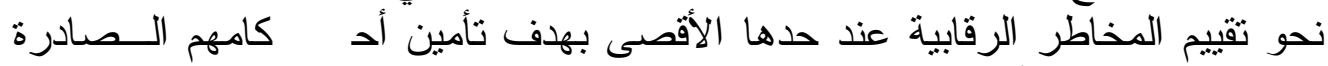

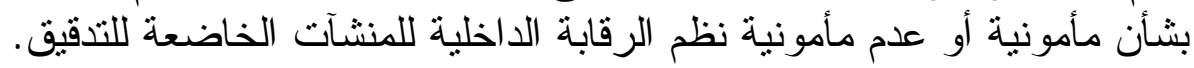



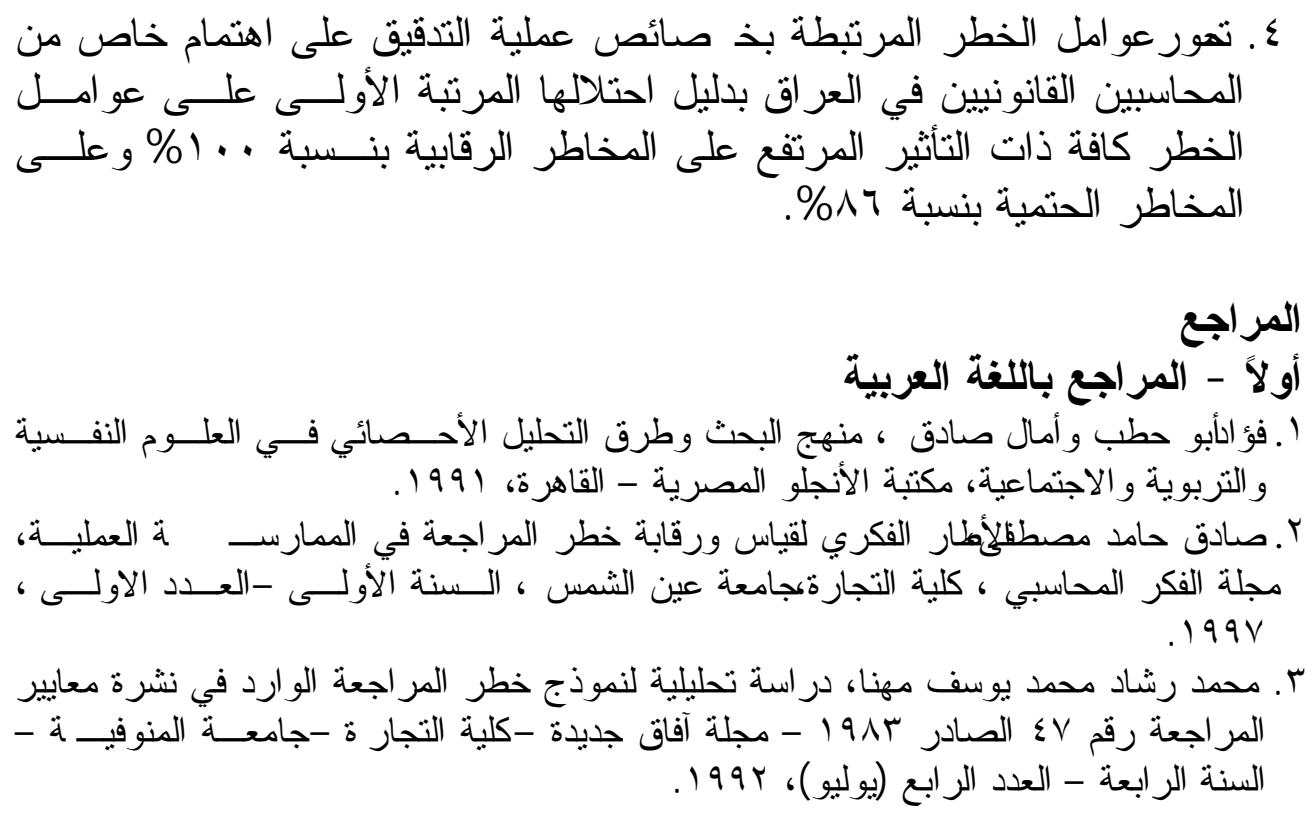

ثانياً - المر اجع باللغة الأجنبية

1. AICPA, Statement On Auditing Standards No.82 Cons Duration Of Fraud In Financial Statement Audit (New York. AICPA February 1976 ).

2. AICPA Statement On Auditing Standards No. 47 ((Audit Risk And Materiality In Conducting, An Audit, (New York. AICPA 1983).

3. AICPA Statement On Auditing Standards No.39 ((Audit Sampling)),(New York. AICPA 1981).

4. Bedard and Graham 2000 ((The Effects Of Decision And Orientation On Risk Factor Identification And Audit Test Planning Auditing ; A Journal Of Practice and Theory.Vol 21 September .

5. Bedard and Graham 1994 [Auditors Knowledge Organization Observations From Audit Practice And Their Lmplie Certifiedation Auditing ] A Journal Of Practice and Theory .Vol 13 (Spring).

6. Beritz.D.E.B.G. Gaber And W.M. Lemon 1987. An EXP - Ermental Study Of Review Of Preliminary Audit Stratege By External Auditors. The Candian Academic Accounting Association Toronto .

7. Canadian Institute Of Chartered Accountant 1980 ,Extent Of Audit Testing ( Toronto;Cica).

8. Clark.Charles T .1974. (Statistical Analysis For Administrative Decisions) South Western Publishing Co. Ohio.

9. Cushing . Barry E. And James K. Loeb beck 1983 (Anatys Pproaches To Audit Risk A Survey And Analysis Auditing) A Journal Of Practice and Theory.

10. Houston.R.M. Peters And J.Pratt 1999 ((The Audit Risk Model Business Risk And Audit Planning Decision))The Accounting Review.Vol 74 -July.

11. Jonstone.K.2000 (Client Acceptance Decision Simultaneous Ettects Of Client Business Risk Auditing Business Risk And Adaptation Auditing) A Journal Of Practice and Theory .Vol 19 Spring. 
12. Kinney.W.R.Jr. 1989. (A Chieved Audit Risk And The Audit Outcome Space Auditing ) A Journal Of Practice and Theory .Vol 8 (Surpisment ) .

13. Kreuzledtand and Wallace." The auditing Risks Masuerment Do they relate to Errors?" Auditing: A Journal of practice and theory. Vol.9 (supplement) .

14. Spires, Eric E.And James A. Yardley 1993((An Empirical Investigation Of The Relalionship Between Auditors Risk Assessment And Detected Misstatements. In Financial Statements )) Paper Presented Of The Accountany Forum .University Of Hlinois October.

15. Waller William S.1993. (( Audit Assessment Of Inherent And Control Risk In Field Sitting )) The Accounting Review Vol 68 (October). 